\title{
WestVirginiaUniversity
}

THE RESEARCH REPOSITORY @ WVU

Graduate Theses, Dissertations, and Problem Reports

2002

\section{Chemical and physical properties of acid mine drainage floc}

Catherine M. Bohan

West Virginia University

Follow this and additional works at: https://researchrepository.wvu.edu/etd

\section{Recommended Citation}

Bohan, Catherine M., "Chemical and physical properties of acid mine drainage floc" (2002). Graduate Theses, Dissertations, and Problem Reports. 1568.

https://researchrepository.wvu.edu/etd/1568

This Thesis is protected by copyright and/or related rights. It has been brought to you by the The Research Repository @WVU with permission from the rights-holder(s). You are free to use this Thesis in any way that is permitted by the copyright and related rights legislation that applies to your use. For other uses you must obtain permission from the rights-holder(s) directly, unless additional rights are indicated by a Creative Commons license in the record and/ or on the work itself. This Thesis has been accepted for inclusion in WVU Graduate Theses, Dissertations, and Problem Reports collection by an authorized administrator of The Research Repository @ WVU. For more information, please contact researchrepository@mail.wvu.edu. 
Chemical and Physical Properties of Acid Mine Drainage Floc

\author{
Catherine M. Bohan ( Maiden: Lenter)
}

Thesis submitted to the

Davis College of Agriculture, Forestry, and Consumer Sciences at West Virginia University in partial fulfillment of the requirements

for the degree of

\author{
Master of Science \\ in \\ Plant and Soil Science
}

Louis M. McDonald Jr., Ph.D., Chair

Jeffery G. Skousen, Ph.D.

Devinder K. Bhumbla, Ph.D.

John Renton, Ph.D.

Division of Plant and Soil Science

\title{
Morgantown, West Virginia 2002
}

Keywords: AMD, floc, settling, sulfate, amorphous iron hydroxides, PZNC Copyright 2002 Catherine M. Bohan 


\section{ABSTRACT \\ Chemical and Physical Properties of Acid Mine Drainage Floc \\ Catherine M. Bohan (Lenter)}

Acid mine drainage is a serious environmental concern in many regions worldwide, but especially in coal and metal mining regions. These acid drainages are often treated with chemicals to raise the $\mathrm{pH}$ of the water and to cause neutralization and precipitation of metals. As neutralization occurs, a looser gelatinous material called "floc" is produced. The effects of neutralizing chemical, $\mathrm{pH}$, sulfate to iron molar ratio, and solids concentration on floc settling properties were determined in synthetic acid mine drainage. Sulfate was the important factor affecting floc physicochemical properties, increasing settling times from $25-125 \%$ and decreasing settling rates from $24-63 \%$. Neutralization $\mathrm{pH}$, treatment chemical cation and initial solids concentration were less important. Ability of treatment to meet discharge standards also decreased with increasing sulfate concentration. An understanding of sulfate and other solution property effects on floc properties may lead to increased treatment efficiency and improved stream water quality. 


\section{Acknowledgements}

The author would like to gratefully acknowledge the invaluable help of Dr. Louis M.

McDonald Jr., E. Joan Wright, Mi Xiao, Dr. William Thayne, Dr. Jeffery G. Skousen, Dr. Devinder K. Bhumbla, Dr. John Renton, Harry "Duke” Brown, Sarah A. Kleckner, and Dr. Paul F. Ziemkiewicz. The financial assistance received from the Division of Plant and Soil Science at West Virginia University is gratefully acknowledged. Support and encouragement from Dr. Barton Baker, Randall and Judith Lenter, and the staff at the West Valley Demonstration Project, U.S. Department of Energy is also appreciated. Thanks be to God for the grace of fortitude, and to my loving husband, Steve- I could not have done this without you! 


\section{Table of Contents}

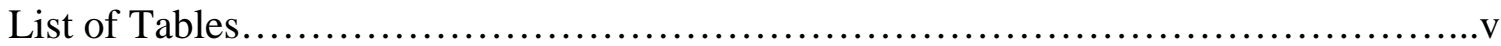

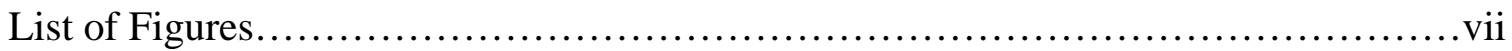

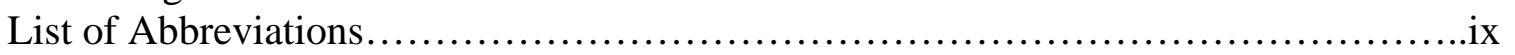

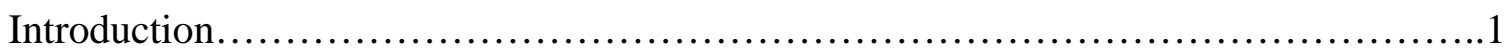

Methods and Materials.............................................................

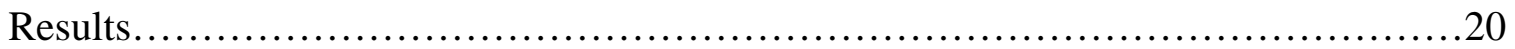

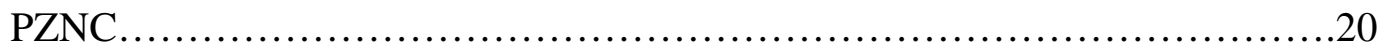

Phase 1 Settling Properties..............................................20

- Settling Times................................................20

- Final Suspended Solids Concentration............................20

- Settling Rates................................................22

Phase 2 Settling Properties............................................. 22

- Settling Times..............................................22

- Final Suspended Solids Concentration...........................26

- Settling Rates..................................................30

Phase 4 Settling Rates................................................... 30

Effects of Solids Concentration on Phase 1 Settling Properties...................30

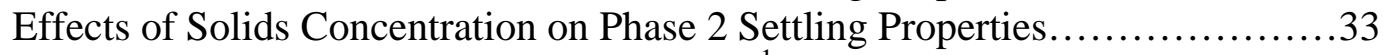

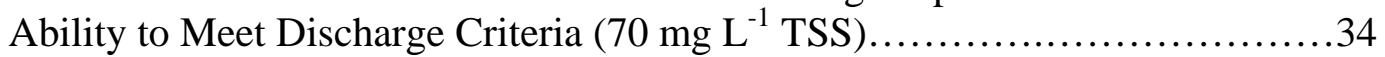

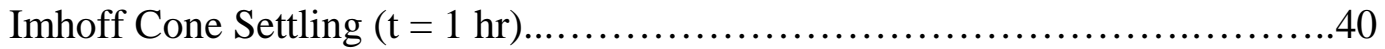

- Settled Floc Mass................................................40

- Settled Floc Volume............................................45

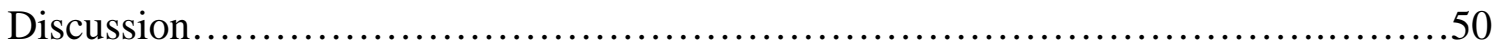

PZNC .................................................................. 50

Effect of Cation on Settling Properties....................................50

Effect of Sulfate to Iron Molar Ratio on Settling Properties....................51

Effect of $\mathrm{pH}$ on Settling Properties ........................................51

Effects of Solids Concentration on Settling Properties........................5 52

Ability to Meet Discharge Criteria (70 mg L-1 TSS) in $\mathrm{t}<300 \mathrm{~s} \ldots \ldots \ldots \ldots \ldots \ldots . \ldots 52$

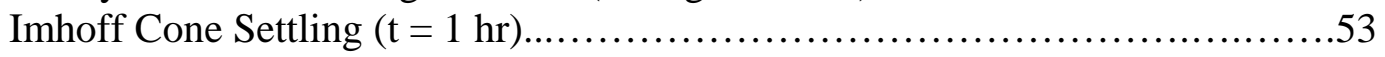

- Settled Floc Mass.............................................53

- Settled Floc Volume...............................................54

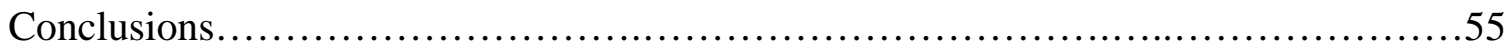

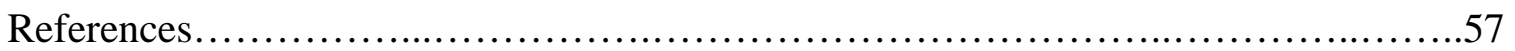




\section{List of Tables}

Table 1. Composition of initial synthetic AMD and neutralizing solutions............16

Table 2. Type III sums of squares and significance levels of main effects, interactions and orthogonal linear contrasts for Phase 1 duration time, final suspended solids concentration, and settling rate when comparing treatment chemical systems.............................................. 21

Table 3. Cation, sulfate to iron molar ratio and $\mathrm{pH}$ effects on the average Phase 1 duration time, final suspended solids concentration, and settling rate when comparing treatment chemical systems.............................22

Table 4. Type III sums of squares and significance levels of main effects, interactions and orthogonal linear contrasts for Phase 2 duration time, final suspended solids concentration, and settling rate when comparing treat-

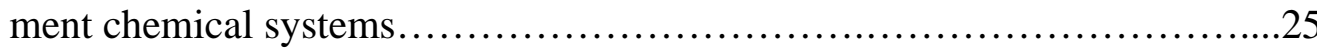

Table 5. Cation, sulfate to iron molar ratio and $\mathrm{pH}$ effects on the average Phase 2 duration time, final suspended solids concentration, and settling rate when comparing treatment chemical systems............................26

Table 6. Type III sums of squares and significance levels of main effects, interactions and orthogonal linear contrasts for Phase 4 settling rate when comparing treatment chemical systems.

Table 7. Cation, sulfate to iron molar ratio and $\mathrm{pH}$ effects on the average Phase 4 final suspended solids concentration and settling rate when comparing treatment chemical systems.

Table 8. Type III sums of squares and significance levels of main effects, interactions and orthogonal linear contrasts for Phase 1 duration time, final suspended solids concentration, and settling rate when comparing different initial suspended solids concentrations in the Na system.

Table 9. Solids, sulfate to iron molar ratio and $\mathrm{pH}$ effects on the average Phase 1 duration time, final suspended solids concentration, and settling rate when comparing different initial suspended solids concentrations in the Na system.

Table 10. Type III sums of squares and significance levels of main effects, interactions and orthogonal linear contrasts for Phase 2 duration time, final suspended solids concentration, and settling rate when comparing different initial suspended solids concentrations in the Na system 
Table 11. Solids, sulfate to iron molar ratio and $\mathrm{pH}$ effects on the average Phase 2 duration time, final suspended solids concentration, and settling rate when comparing different initial solids concentrations in the $\mathrm{Na}$ system.....40

Table 12. Type III sums of squares and significance levels of main effects, interactions and orthogonal linear contrasts for settling time required to reach the NPDES discharge limit of $70 \mathrm{mg} \mathrm{L}^{-1}$ and initial settling rate $(\mathrm{t}<300 \mathrm{~s})$

Table 13. Cation, sulfate to iron molar ratio and $\mathrm{pH}$ effects on the average settled floc mass and volume, initial settling rates and time.

Table 14. Type III sums of squares and significance levels of main effects, interactions and orthogonal linear contrasts for average settled floc mass and volume after one hour in Imhoff ${ }^{\circledR}$ cones. .48 


\section{List of Figures}

Figure 1. The hydrolysis species of $\mathrm{Fe}$ (III) in equilibrium with amorphous-Fe and sulfate...

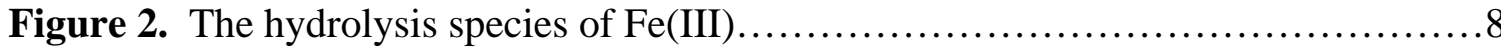

Figure 3. Typical settling curve for synthetic acid mine drainage floc with settling phases denoted by name and number.

Figure 4. Average settling time (s) for the sodium and ammonium flocs at the end of phase 1 as affected by $\mathrm{pH}$ and sulfate to iron molar ratio. Error bars represent standard deviation calculated for each subset of treatment interactions presented. $\mathrm{df}=5$.

Figure 5. Average suspended solids concentration $\left(\mathrm{mg} \mathrm{L}^{-1}\right)$ at the end of phase 1 as affected by $\mathrm{pH}$ and sulfate to iron molar ratio. Error bars represent standard deviation calculated for each subset of treatment interactions presented. $\mathrm{df}=5$

Figure 6. Average settling time (s) at the end of Phase 2 as affected by treatment cation and sulfate to iron molar ratio. Error bars represent standard deviation calculated for each subset of treatment interactions presented. $\mathrm{df}=8$

Figure 7. Average settling time at the end of Phase 2 as affected by $\mathrm{pH}$ and sulfate to iron molar ratio. Error bars represent standard deviation calculated for each subset of treatment interactions presented. $\mathrm{df}=5$

Figure 8. Average final suspended solids concentration in Phase 2 as affected by treatment cation and sulfate to iron molar ratio. Error bars represent standard deviation calculated for each subset of treatment interactions presented. $\mathrm{df}=8$

Figure 9. Average final suspended solids concentration for Phase 2 as affected by $\mathrm{pH}$ and sulfate to iron molar ratio. Error bars represent standard deviation calculated for each subset of treatment interactions presented. $\mathrm{df}=5$

Figure 10. Average settling rate for Phase 2 as affected by $\mathrm{pH}$ and sulfate to iron molar ratio. Error bars represent standard deviation calculated for each subset of treatment interactions presented. $\mathrm{df}=5$. 
Figure 11. Average settling time (s) for Phase 1 as affected by $\mathrm{pH}$ and initial suspended solids concentration. Error bars represent standard deviation calculated for each subset of treatment interactions presented. $\mathrm{df}=8$.

Figure 12. Average settling time in Phase 2 as affected by initial experiment suspended solids concentration and sulfate to iron molar ratio. Error bars represent standard deviation calculated for each subset of treatment interactions presented. $\mathrm{df}=8$.

Figure 13. Average final Phase 2 suspended solids concentration as affected by initial experiment suspended solids concentration and sulfate to iron molar ratio. Error bars represent standard deviation calculated for each subset of treatment interactions presented. $\mathrm{df}=8$

Figure 14. Average settling rate in Phase 2 as affected by initial experiment suspended solids concentration and sulfate to iron molar ratio. Error bars represent standard deviation calculated for each subset of treatment interactions presented. $\mathrm{df}=8$.

Figure 15. Settling curves for each sulfate to iron molar ratio in the sodium system. Discharge limit ( $\left.70 \mathrm{mg} \mathrm{L}^{-1} \mathrm{TSS}\right)$ indicated by the solid line

Figure 16. Settling curves for each sulfate to iron molar ratio in the ammonium system. Discharge limit (70 $\left.\mathrm{mg} \mathrm{L}^{-1} \mathrm{TSS}\right)$ indicated by the solid line.

Figure 17. Average settling time to reach discharge limits as affected by cation and sulfate to iron molar ratio. Error bars represent standard deviation calculated for each subset of treatment interactions presented. $\mathrm{df}=8$.

Figure 18. Average settled sludge mass (g) for the Imhoff Settling Cones as affected by $\mathrm{pH}$ and sulfate to iron molar ratio. 


\section{List of Abbreviations}

$\begin{array}{ll}\text { AMD } & \text { Acid Mine Drainage } \\ \text { EC } & \text { Electrical Conductivity } \\ \text { df } & \text { Degrees of Freedom } \\ \text { HFO } & \text { Hydrous Ferric Oxide } \\ \text { hr } & \text { hour } \\ \text { L } & \text { liters } \\ \text { mg } & \text { milligrams } \\ \text { NPDES } & \text { National Pollution Discharge Elimination System } \\ \text { PZNC } & \text { Point of Zero Net Charge } \\ \text { s } & \text { seconds } \\ \text { SMCRA } & \text { Surface Mining Control and Reclamation Act } \\ \text { SS } & \text { Suspended Solids or Sums of Squares } \\ \text { TSS } & \text { Total Suspended Solids } \\ \text { ZPC } & \text { Zero Point of Charge }\end{array}$




\section{Introduction}

Acid drainage, whether naturally occurring or due to anthropogenic activities, has been the subject of research and concern worldwide (Chang and Cockerham, 1994; Yernberg, 2000). Governmental agencies and mining companies alike have joined forces to study the problem and share information regarding treatment and remediation technologies. Canadian officials recognize acid drainage as, "the largest environmental liability facing the Canadian mining industry" (Yernberg, 2000). In the United States alone, an estimated 10,000 stream miles and 29,000 surface acres have been seriously influenced by such drainage (Yernberg, 2000).

More specifically, acid mine drainage, hereafter called AMD, has been named the worst problem, causing the most environmental trouble, in Appalachia since coal was first mined (Peck et al. 1979; Waldron, 1991). Of the 28,000 stream miles (in more than 9,000 streams and rivers) in the state of West Virginia alone, 17,455 were assessed in 1989 by the West Virginia Division of Natural Resources for their ability to support designated uses. Toxic metals from mine drainage affected water quality in 2,427 miles of 477 streams (Waldron, 1991, p. 182-183).

Acid drainage is a low $\mathrm{pH}$, sulfate-rich solution with high acidity and metal (particularly iron, aluminum, manganese, lead, copper, cadmium, and zinc) concentrations resulting from the oxidation of sulfide minerals exposed during coal and metal mining, highway construction, and other deep excavation (Connell and Miller, 1984; Nordstrom, 1991; Rose and Cravotta, 1998; Singer and Stumm, 1970; Singh et al., 1997; Yernberg, 2000). In the case of mining, it can be introduced to the environment surrounding a mine via surface runoff or deep-mine drainage to local waterways. AMD is a serious problem from coal refuse piles and abandoned mine sites left uncovered or unfilled and unvegetated. Approximately 54,000 acres of coal refuse and 1.6 million acres of abandoned coal mines exist in the state of West Virginia (Ferrell, 1986). Naturally occurring bacteria of the species Thiobacillus ferroxidans have been identified as catalysts in the aqueous oxidation of iron (Bigham et al., 1996a; Singer and Stumm, 1970; Singh et al., 1997). These bacteria are capable of significantly increasing the amount of acid generated in drainage situations. 
The contaminated water flowing from the affected sites has been shown to have a negative effect on stream health and diversity. Stream ecology shifts to domination by a few pollution-tolerant organisms, if the stream is still habitable at all (Chang and Cockerham, 1994; Connell and Miller, 1984; Gray, 1997; Kleinow and Goodrich, 1994; Maggard and Kirk, 1999; Singh et al., 1997; Stuart et al., 1999; Yernberg, 2000). Metals incorporated into the stream sediments can act as secondary contamination sources (Macklin et al., 1997), making their removal prior to drainage discharge all the more important. The contamination can also effect humans who use such streams and rivers as their only source of potable water (Connell and Miller, 1984).

Generally speaking, sites are abandoned and left unreclaimed for two major reasons: either the mining company declared bankruptcy, or the site was mined before the passage of the Surface Mining Control and Reclamation Act of 1977 (SMCRA). In such cases, any treatment of AMD that shows improvement in discharge quality is generally accepted. Treatment at these locations is financed by the Special Reclamation Fund, designed to reclaim forfeited sites. Unfortunately, there is not enough money in the program to enable treatment of all of the sites needing repair, as the only funding comes from bond forfeiture by bankrupt companies and a small per ton tax on mined coal.

Since the passage of SMCRA, regulations stipulate that AMD contaminated water from current operations be treated, as necessary, to neutralize acidity and remove metals before being discharged to a water supply (Evangelou, 1998; Skousen, 1996). Treatment processes must effect the reduction of total iron concentrations to less than $7.0 \mathrm{mg} \mathrm{L}^{-1}$ ( $<3.5 \mathrm{mg} \mathrm{L}^{-1}$ average of daily values for 30 consecutive discharge days) and raise $\mathrm{pH}$ within the range of 6.0 to 9.0 (as would be found in many natural waters) to be approved under these standards (Evangelou, 1998).

In considering these regulations against financial constraints, maximizing treatment efficiency through economical methods has become the focus of method development and selection. This approach has resulted in the development of both active and passive treatment methods (Holtzen and Smith, 1998). The concept behind all such methods is to oxidize the metals in solution and raise the $\mathrm{pH}$, creating metal precipitates. Active designs require regular maintenance and more equipment than passive systems. 
These sites usually have large flows to which a specific treatment chemical must be regularly added to effect continuous metal removal and increase $\mathrm{pH}$. Passive system designs include constructed wetlands, limestone filters, aerobic limestone channels, and anoxic limestone drains in coordination with settling ponds designed to catch metal precipitates. Such treatments are selected for remote, small, or intermittent flows and are meant to be relatively maintenance-free. Other less conventional abatement technologies currently undergoing investigation include the use of dredged harbour sediments with municipal incinerator ash (Tyson, 1997), ceramic membranes (Stewart et al., 1997), synthetic zeolites from coal fly ash (Moreno et al., 2001), ionic state modification (HPT Research, Inc., 2000), wet limestone scrubber byproducts (Ashby, 1998), permeable reactive barriers (Waybrant et al., 1998), and bioremediation (Bigham et al., 1996a; Steed et al., 1996; Yernberg, 2000).

All conventional active treatment methods use basic compounds to neutralize acidity and form metal precipitates. Some of the most common chemicals chosen by mine operators include sodium hydroxide, anhydrous ammonia, sodium carbonate, calcium oxide, calcium carbonate, and calcium hydroxide (Skousen, 1988). All of these developed treatment processes result in the production of floc, or sludge, a generally amorphous, precipitate of metal hydroxides, carbonates, or hydroxy sulfates (Brown et al., 1994a). If the drainage is a high volume flow or contains particularly high concentrations of iron, floc can be produced in large quantities. Periodically, it may be necessary to dredge settling ponds of this hydrous ferric oxide (HFO) material and dispose of it elsewhere to ensure the continued operation of the system.

Numerous researchers have devoted time to the study of HFO formation with an aim at developing alternative uses for the material rather than disposing of it, eventually focusing very specifically on the material's physicochemical properties. Parida and Das (1996) and Nakamura and Kurokawa (1995) listed coloring pigments, catalyst characteristics, coatings, ferrites, and magnetic recording media as potential use options that have prompted the study of HFO preparation techniques. Nakamura and Kurokawa (1995) also cited use of the material in gas sensors as motivation for inquiries into its properties. Melikhov et al. (1987) noted that the material is used to prepare sorbents. Dousma and de Bruyn (1976) identified four stages in the hydrolysis process of iron 
solutions and proposed a model to explain their findings. The model was later expanded to account for two stages in the aging process (Dousma and de Bruyn, 1978). Melikhov et al. (1987) studied early precipitation kinetics, primary particle characteristics, and formation rates in chloride and nitrate solutions. An analysis of kinetic data also provided information on the interfacial tension of the precipitate (Dousma and de Bruyn, 1979). Parida and Das (1996) considered the effect of sulfate on the material's properties and developed a method to precipitate homogenous particles. The effect of $\mathrm{pH}$ on mineral development from amorphous ferrihydrite has been considered, as well (Schwertmann and Murad, 1983). Although these studies have begun to explain the characteristics of HFO particles, more research is still required to fully elucidate the effect of treatment conditions on HFO physicochemical properties.

Researchers have given particular emphasis to the study of the material's structure. "Structure," loosely defined, is any semipermanent association of units with some ability to resist deformation (Glasrud et al., 1993). Units can be particles or various combinations of particle types. According to Glasgow (1989), floc is more generally a "loose, porous agglomeration of smaller particles that forms as a consequence of interparticle collisions." Early work in the area of floc structure focused on computer simulations of particle collision and aggregation processes (Sutherland, 1966, 1967; Sutherland and Goodarz-Nia, 1971; Vold, 1963). Dousma and de Bruyn (1979) identified surface-nucleation processes as a dominant contributor to floc growth. Floc growth is also controlled by five collisional mechanisms: Brownian motion, laminar shear, turbulent shear, turbulent inertia, and differential sedimentation (Glasgow, 1989). Agglomeration can only occur when the repulsive potential barrier between primary particles is suppressed or counteracted by some other condition (Glasgow, 1989). Aluminum hydroxide floc was found to usually consist of 3 components: suspended solids, hydrolyzed poly-metal ions, and water trapped within the floc during floc growth (Tambo and Watanabe, 1979). Given the similarities between the chemistry of aluminum and iron oxidation, one may suppose iron hydroxide floc structure to be comparable. Rapid iron precipitation, as occurs in high flows or high iron concentrations, yields small particles (Diz et al., 1999). These particles eventually combine to produce larger flocs with more internal water incorporated (Diz, 1999; 
Glasgow, 1989). Longer retention times are required to permit this agglomeration process to occur (Diz, 1999). While these particles may settle more rapidly than smaller flocs once formed, they tend to result in increased sludge volumes overall (Glasgow, 1989). Ackman (1982) also noted a correlation between low total suspended solids and large volumes as a result of active treatments.

Use of a multi-layer structure model began as a possible explanation for observed settling and flow behavior in kaolinite suspensions (Michaels and Bolger 1962a, 1962b). Further study of the relationship between floc density and floc diameter of iron hydroxide flocs provided additional support for the model (Lagvankar and Gemmel, 1968). Similar work was completed by Tambo and Watanabe (1979) for aluminum hydroxide flocs. This concept was more specifically defined as a four level floc structure through a theoretical model (van de Ven and Hunter, 1977). The four layers have been identified as follows: (1) primary particles, (2) dense flocculi comprised of primary particles, (3) flocs composed of those flocculi formed at the highest level of shear rate during flocculation, and (4) weak aggregates formed from those flocs. For aluminum hydroxide flocs with kaolinite, all bonds within and among the levels and different parts are elastic. (François and Van Haute, 1985) In iron hydroxide precipitation, the primary particles are believed to be tetramers of $\left[\mathrm{Fe}(\mathrm{OH})_{3}\right]_{4}$ (Melikov et al., 1987). These primary particles may be quite small in active treatment systems due to a large chemical driving force (Dempsey and Jeon, 2001; Diz et al., 1999). This four layer non-homogenous floc structure is valid for aluminum hydroxide flocs formed in very dilute suspensions with the use of hydrolyzing metal salts (François and Van Haute, 1985). More concentrated solutions, as may be found in AMD, may yield a different structure.

Many AMD flows contain significant concentrations of sulfate. The solubility of iron(III) hydroxide (amorphous) in solution with sulfate is controlled by the following reactions, assuming no sulfate bearing solids:

$$
\begin{array}{ll}
\mathrm{Fe}(\mathrm{OH})_{3}(\text { amorph })+3 \mathrm{H}^{+} \leftrightarrow \mathrm{Fe}^{3+}+3 \mathrm{H}_{2} \mathrm{O} & \log \mathrm{K}=3.54 \\
\mathrm{Fe}^{3+}+\mathrm{H}_{2} \mathrm{O} \leftrightarrow \mathrm{FeOH}^{2+}+\mathrm{H}^{+} & \log \mathrm{K}=-2.19 \\
\mathrm{Fe}^{3+}+2 \mathrm{H}_{2} \mathrm{O} \leftrightarrow \mathrm{Fe}(\mathrm{OH})_{2}^{+}+2 \mathrm{H}^{+} & \log \mathrm{K}=-5.69
\end{array}
$$




$$
\begin{array}{lr}
\mathrm{Fe}^{3+}+3 \mathrm{H}_{2} \mathrm{O} \leftrightarrow \mathrm{Fe}(\mathrm{OH})_{3}^{\mathrm{o}}+3 \mathrm{H}^{+} & \log \mathrm{K}=-13.09 \\
\mathrm{Fe}^{3+}+4 \mathrm{H}_{2} \mathrm{O} \leftrightarrow \mathrm{Fe}(\mathrm{OH})_{4}^{-}+4 \mathrm{H}^{+} & \log \mathrm{K}=-21.59 \\
2 \mathrm{Fe}^{3+}+2 \mathrm{H}_{2} \mathrm{O} \leftrightarrow \mathrm{Fe}_{2}(\mathrm{OH})_{2}^{4+}+2 \mathrm{H}^{+} & \log \mathrm{K}=-2.90 \\
\mathrm{Fe}^{3+}+\mathrm{SO}_{4}^{2-} \leftrightarrow \mathrm{FeSO}_{4}^{+} & \log \mathrm{K}=4.15
\end{array}
$$

(Lindsay, 1979)

Based on these equilibrium constants, iron(III) hydroxide demonstrates a solubility minimum around $\mathrm{pH} 8$ (Figure 1). Without sulfate, the calculated solubility minimum is between pH 7.4 and pH 8.5 (Figure 2) (Lindsay, 1979). This range is in agreement with the experimental results of Lahann (1976). Based on these calculations, one would conclude that the presence of sulfate complexes produces an apparent shift in solubility. For the $\mathrm{pH}$ range under consideration in this study ( $\mathrm{pH}$ 6-9), assuming a lack of sulfate bearing minerals would be consistent with Bigham et al. (1996a; 1996b). Iron sulfate minerals such as jarosite and schwertmannite are not stable in this range, whereas HFO and goethite $(\alpha-\mathrm{FeOOH})$ predominate (Bigham et al., 1996b; Langmuir, 1997; Lindsay, 1979).

Settling generally follows a pattern easily described by four phases: reflocculation, initial settling, transition, and compression (Figure 3) (Lee et al., 1983). Settleability is governed by numerous factors including: particle size and shape, coagulation rates, initial particle concentration in suspension, surface electrical potential, solution composition, and type of minerals present (Evangelou, 1990). Particle size and shape may be affected by reaction rate as previously discussed. Variations may also be observed between treatments with different sulfate to iron molar ratios due to the inhibitory effect of sulfate on crystal formation (Dousma et al., 1979). As the suspended solids concentration increases, the likelihood of particle interaction also increases, augmenting rates of coagulation. Stoke's Law assumes uniform particle density among particles. However, such may not be the case for floc particles created using differing treatment chemicals or initial solution compositions. Research already indicates that simple theories like Stoke's flow in suspensions at the dilute limit do not clearly reveal settling mechanisms in more complex systems (Glasrud et al., 1993). Such precipitates 


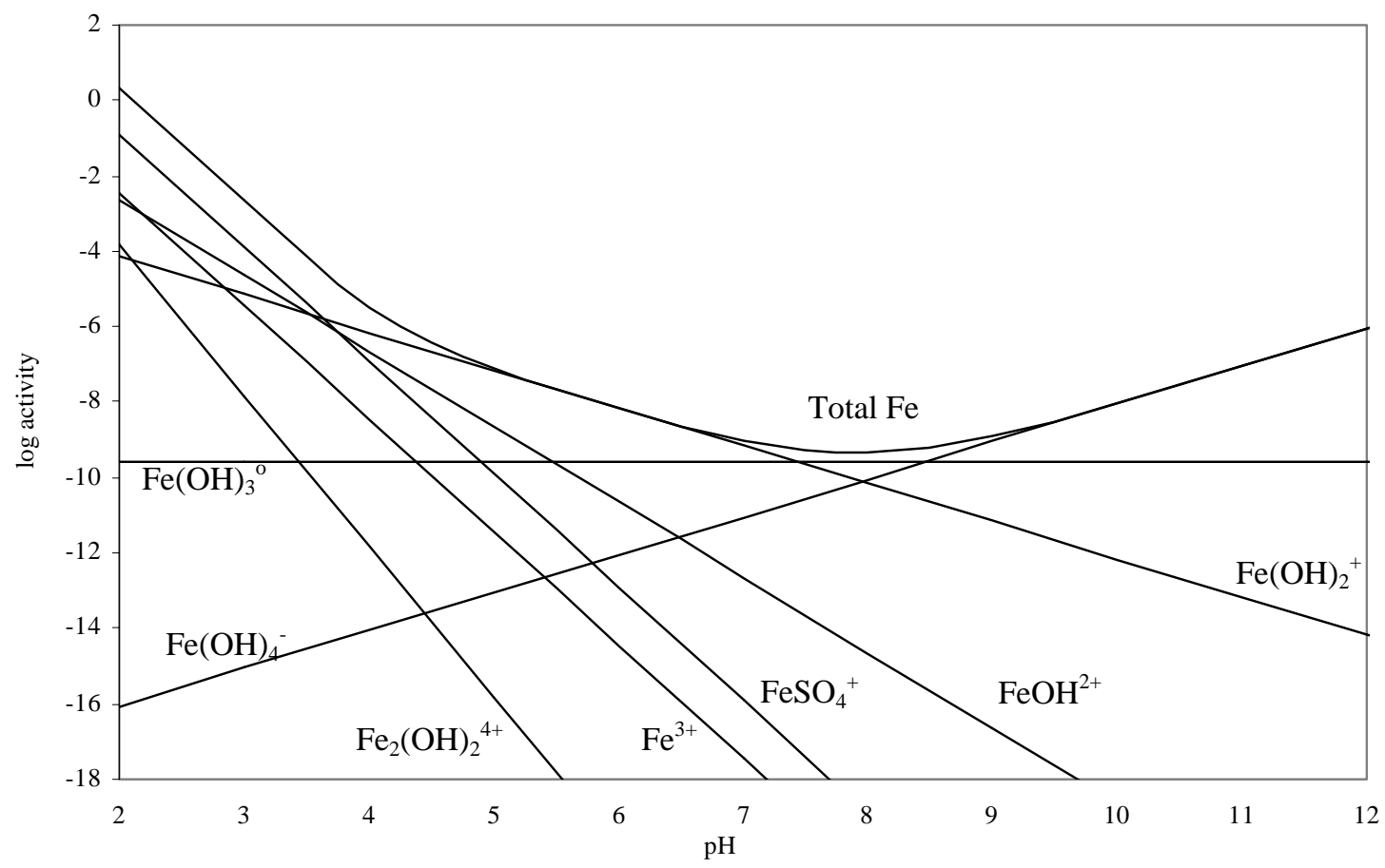

Figure 1. The hydrolysis species of Fe(III) in equilibrium with amorphous-Fe and sulfate. 


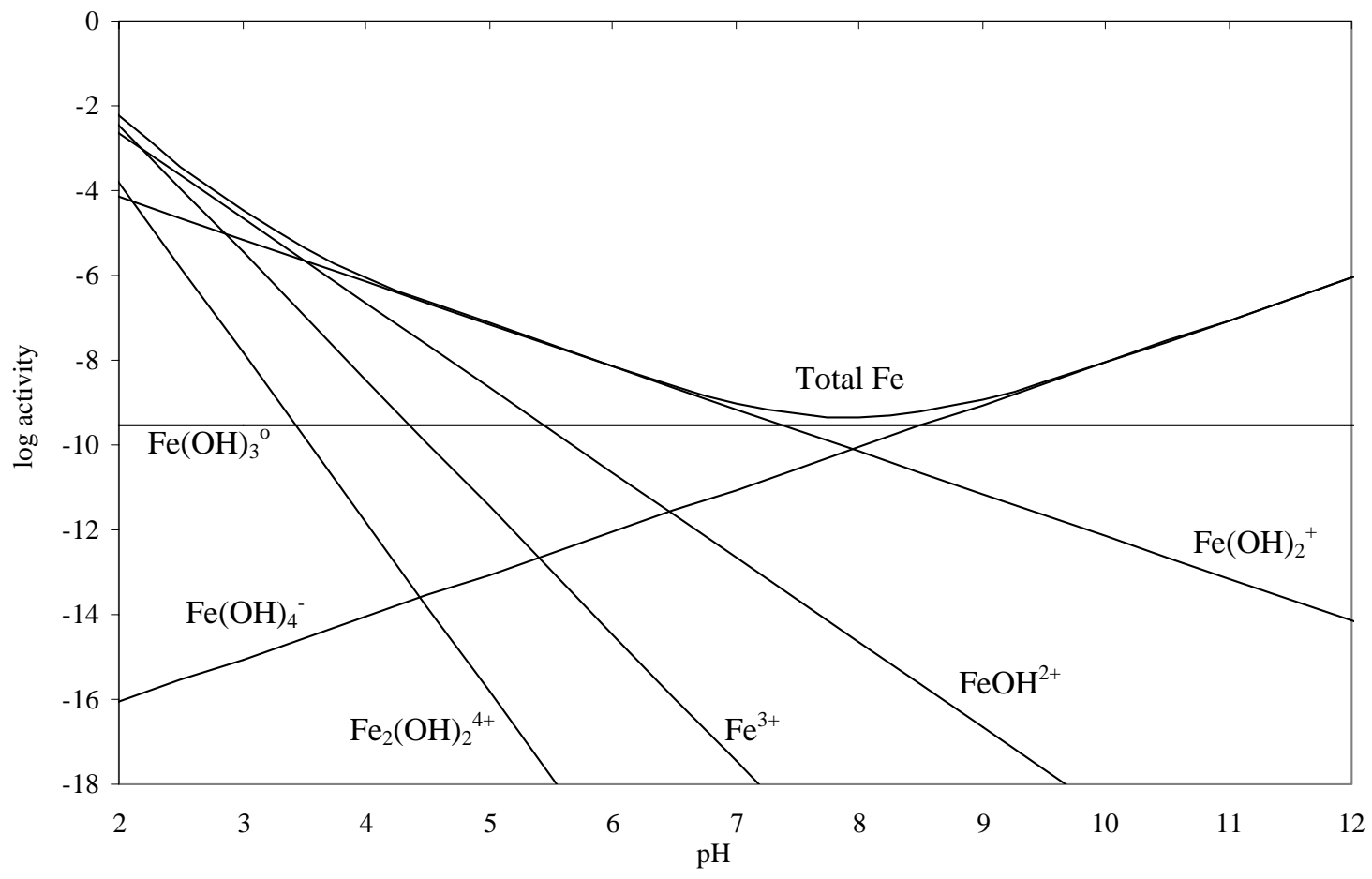

Figure 2. The hydrolysis species of Fe(III). 


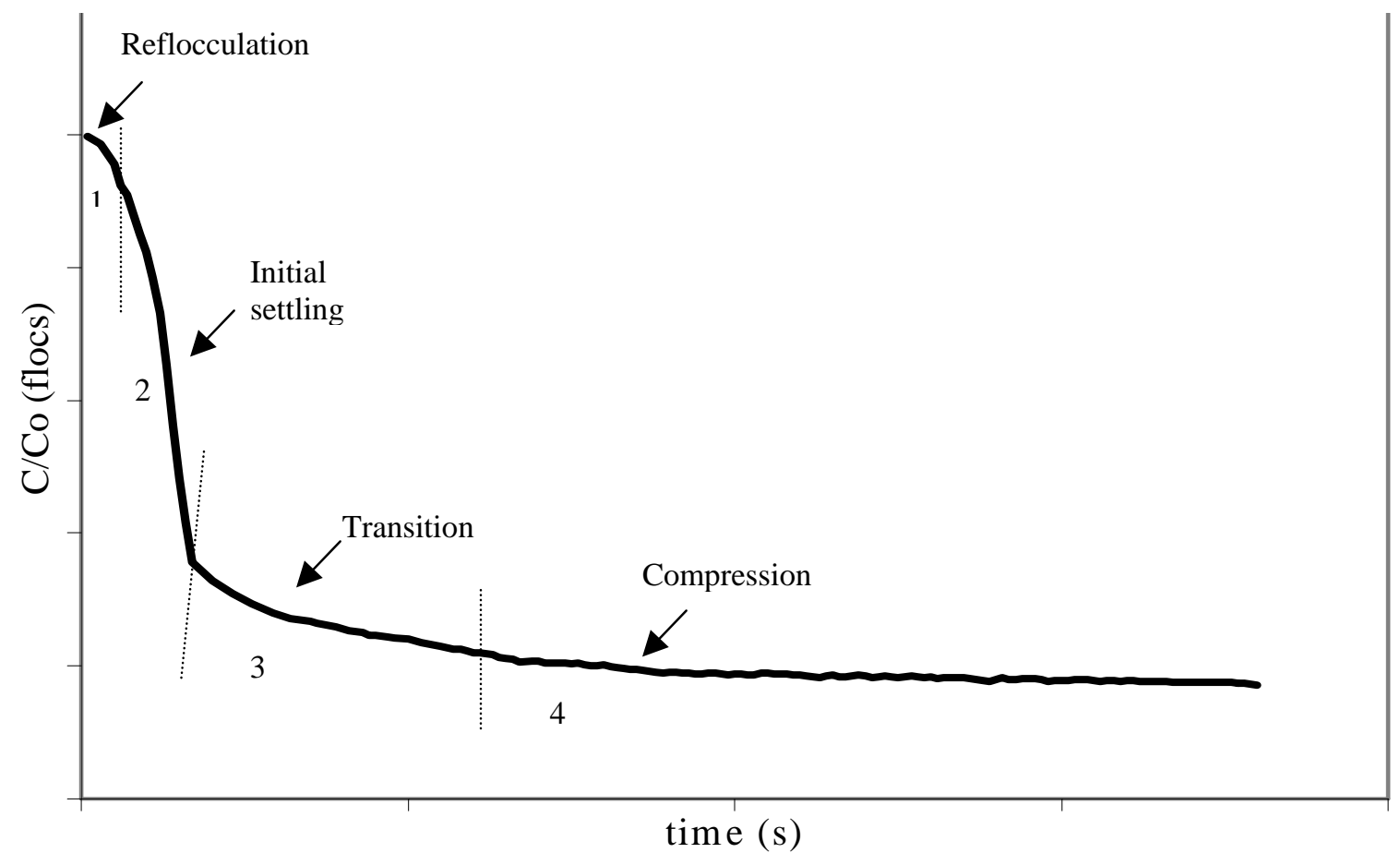

Figure 3. Typical settling curve for synthetic acid mine drainage floc with settling phases denoted by name and number. 
may also exhibit different surface charge potentials since their mineral compositions may be different.

Double-layer swelling also controls flocculation/dispersion processes. The separation distance between particles in solution or the sedimented floc is related to the thickness of the double-layer. The thickness of the double-layer $(\mathrm{R})$ in centimeters is governed by the following equation:

$$
\mathrm{R}=\left(\frac{\varepsilon \kappa \mathrm{T}}{8 \pi \mathrm{e}^{2} \mathrm{NI}}\right)^{\frac{1}{2}}
$$

where

$$
\begin{aligned}
\mathrm{e} & =\text { charge of electron }(\mathrm{C}) \\
\varepsilon & =\text { dielectric constant }\left(\mathrm{C}^{2}\right) *\left(\mathrm{~N}^{*} \mathrm{~cm}^{2}\right)^{-1} \\
\kappa \mathrm{T} & =\text { Boltzman constant times absolute temperature }\left(\mathrm{J}^{\circ} \mathrm{K}^{-1}\right)\left({ }^{\circ} \mathrm{K}\right) \\
\mathrm{N} & =\text { Avogadro's number }(\mathrm{mmol}) \\
\mathrm{I} & =\text { Ionic strength }\left(\mathrm{mmol} \mathrm{mL} \mathrm{m}^{-1}\right)
\end{aligned}
$$

(Stumm and Morgan, 1981)

This relationship lacks any ion-specific parameters and so the thickness depends only on ionic strength at constant $\mathrm{pH}$ and temperature. Therefore, if the ionic strength also remains constant, any differences observed will be a function of the cation in the neutralizing chemical.

The solubility minimum in a given system corresponds to the $\mathrm{pH}$ of point of zero net charge (PZNC). Solids have a net positive charge below the $\mathrm{pH}$ of PZNC and a net negative charge above the $\mathrm{pH}$ of PZNC. At the PZNC, the net variable surface charge on a surface area basis approaches zero, allowing maximum colloid coagulation (Evangelou, 1998; Singh and Uehara, 1986). Therefore, flocculation and settling should be optimal because the repulsive forces between like-charged particles are minimized. Ideally, AMD treatment systems should treat only to the PZNC to effect maximum iron removal.

Specific adsorption, types of ions and complexes in solution and the mineral, 
ionic strength, and ion activity control the position of the PZNC. For example, specific adsorption of various ions can shift the PZNC to a higher or lower $\mathrm{pH}$. Cations forming outer-sphere complexes with variably charged minerals (e.g. metal oxides) generally shift the PZNC to lower $\mathrm{pH}$ values while anions forming outer-sphere complexes shift the PZNC to a higher $\mathrm{pH}$. The reverse is true for cations and anions forming inner sphere complexes. HFO in the presence of both chloride and sulfate exhibits a shift in PZNC of only $0.05 \mathrm{pH}$ units (Kanungo, 1994). Kanungo (1994) suggested that this phenomenon is caused by a preferential adsorption of $\mathrm{Cl}^{-}$over $\mathrm{SO}_{4}{ }^{2-}$ due to geometry and coordination chemistry factors. Metal ion precipitation may also be controlled by ion-pairing, or complexation effect (Evangelou, 1998). Such composition-based effects must be taken into account for the treatment of each individual AMD source (Evangelou, 1998; Sposito, 1981). Baltpurvins et al. (1996) further states that even slight changes in solution composition can cause an optimized treatment system to fail.

Sulfate effects on HFO physicochemical properties have been the subject of multiple investigations. Many of these studies have focused on the effect of sulfate on HFO phase and mineral formation; sulfate adsorption mechanisms; effects of complexation on solubility, particle growth, and surface charge properties; and changes in solution acidity due to sulfate. Some researchers believe that sulfate is a better indicator than iron to assess watershed impacts from mining (Rikard and Kunkle, 1990). Sulfate to iron molar ratios and dissolved sulfate concentrations have been shown to affect the HFO phases and minerals that form from AMD (Bigham et al., 1996a; Brady et al., 1986; Parida and Das, 1996; Rose and Ghazi, 1997). As the sulfate to iron molar ratio increased from $0, \mathrm{HFO}$ gave way to goethite. As the ratio increased to $>1.5$, a ferrihydrite-like material [schwertmannite] was formed and goethite disappeared (Brady et al., 1986). Increasing $\mathrm{SO}_{4}{ }^{2-}$ concentration also resulted in reduced crystallinity and yellower-colored solids (Brady et al., 1986). Particles formed without $\mathrm{SO}_{4}{ }^{2-}$ were very small and highly aggregated (Brady et al., 1986). As $\mathrm{SO}_{4}{ }^{2-}$ concentration increased, final particle size increased and became more complex, finger-like projections (Brady et al., 1986). Association of sulfate to HFO may be via weak electrostatic attractions (Persson and Lovgren, 1996; Rose and Ghazi, 1997; Parfitt and Smart, 1978). It may also be adsorbed onto hydrous alumina and HFO surfaces by binuclear bridging (Parfitt and 
Smart, 1978), or ring structures (Rajan, 1978). This sorption on the surface of growing HFO particles may block the attachment of $\mathrm{Fe} / \mathrm{OH}$ growth units, thereby inhibiting particle growth (Diz et al., 1999). Although our solubility diagrams to not address the formation of sulfate bearing minerals, sulfate may complex with free ferric ion in solution in more ways than we represent. This complexation effect has been shown to further decrease HFO growth rates since less free ferric iron is available for incorporation into already formed surfaces (Diz et al., 1999). At low sulfate concentrations, sulfate adsorbs preferentially on positively charged sites, displacing coordinated water (Rajan, 1978). As the surface saturation increases, sulfate begins to displace hydroxide ions (Rajan, 1978). The presence of $\mathrm{SO}_{4}{ }^{2-}$ in solution results in a decrease in the iron oxygenation rate constant (Sung and Morgan, 1980). Sorbed sulfate has also been shown to decrease the dissolution rates of AMD mineral particles, potentially showing a correlation to surface reactivity (Bigham et al., 1996a). Sulfate also can be expected to be retained as a counterion in the diffuse double layer (DDL). High concentrations of sulfate may result in a shift in the PZNC to lower $\mathrm{pH}$ if sulfate forms inner-sphere complexes or to higher $\mathrm{pH}$ if it forms outer-sphere complexes (Evangelou, 1998). While Breeuwsma and Lyklema (1973) reported an increase in the $\mathrm{pH}_{\mathrm{ZPC}}$ of hematite on addition of sulfate, Rajan (1978) indicates these results may be inaccurate since the $\mathrm{pH}_{\mathrm{ZPC}}$ was determined from acid base titration curves, but sulfate was not treated as a potential determining ion. Sulfate retained by precipitated HFO aggregates upon formation may be desorbed as $\mathrm{pH}$ is increased during acid water treatment (Rose and Ghazi, 1997), complicating treatment endpoint $\mathrm{pH}$ selection. Finally, replacement of coordinated $\mathrm{SO}_{4}{ }^{2-}$ during crystallization of HFO precipitates results in an increase in acidity (Lahann, 1976). Variations in the sulfate to iron molar ratio may also affect treatment efficiency. Many of these variables should be studied to further understand the effects of sulfate on the physicochemical properties of amorphous HFO.

Some studies indicate that there are differences in the floc produced when using different chemicals for treatment (Ackman, 1982; Brown et al., 1994a). Brown et al. (1994a, 1994b) evaluated four chemicals on four AMD sources of differing compositions. However, this study normalized the results based on the mass of floc 
produced per mass of treatment chemical used. Since these chemicals were inherently different, with unique molecular weights, it would seem that the results should have been normalized based on the concentration of metals removed from the water samples. If all chemicals are added in the same way, the possible differences in floc nucleation and particle size created by varying base addition rates should be minimized, allowing comparison based solely on differences in treatment chemical. Any variations in settleability and floc volume should then be due to variations in solution composition. Treatment with sodium or ammonium hydroxide may result in different floc volumes due to the differences in hydration energies. Any effects on the zero point of charge may also become apparent at this point if the cations form inner or outer-sphere complexes, which can shift the PZNC value for metal-oxides (Evangelou, 1998).

In considering the effect of treatment chemical on floc characteristics, the procedure of Brown et al. (1994a) involved the coprecipitation of manganese and iron when treating to various $\mathrm{pH}$ levels. As a result, the measure of efficiency was based on the best combined removal of the two metals. The current study focused on iron alone since the presence of manganese introduces several additional variables for consideration. Although the oxidation rates of $\mathrm{Mn}$ are negligible in homogenous solutions (Diem and Stumm, 1984), Mn is catalytically oxidized on surfaces, including iron oxide surfaces (Davies and Morgan, 1989; Singh et al., 1997). In particular, $\mathrm{Mn}^{2+}$ can act as a potential determining ion in the presence of HFO, forming inner-sphere complexes on the iron precipitate surface and, in effect, creating a new surface (Davies and Morgan, 1989). This formation could effectively mask effects due to treatment chemical cations. The proton acidity generated during manganese oxidation would also be an undesirable complication in the determination of treatment efficiency. If one wishes to determine the surface properties of the HFO alone, manganese must be eliminated as a solution component.

The desirable characteristics of any produced floc seem to be rapid settleability with minimum volume, yet maximum production, or maximum iron removal from AMD (Zhou et al., 1994; Evangelou, 1990; Przepiora et al., 1997; Evangelou and Karathanasis, 1991). Glasgow (1989) adds that flocs must be large enough and dense enough to meet sedimentation requirements, aggregates strong enough to resist 
disruptive hydrodynamic gradients accompanying treatment, and structure and permeability such that dewatering minimizes disposable sludge volume. According to Ackman (1982), the physical and chemical characteristics of floc vary depending on the composition of the AMD, the neutralizing chemical, and the mechanical mixing or aeration device that may be used in coordination with the chemical. Based on these factors, it is reasonable to suggest that variations in sulfate concentration, sulfate to iron molar ratio, treatment chemical, treatment end $\mathrm{pH}$, and initial suspended solids concentration may all affect settling rates and times, final settled volumes, and final settled masses. Since Diz et al. (1999) found that floc growth was inhibited by the presence of sulfate, it is logical to suggest that settling times and/or rates may also be slowed. Differences in the hydrated radius of the treatment chemical coordinating cation or the sulfate concentration (relative to that of iron) may affect the final settled volumes. The treatment endpoint $\mathrm{pH}$ may also result in differences in final volumes or mass of settled floc. Another factor to consider is the initial suspended solids concentration created by treatment. This concentration may increase the settling rate, affect the total (final) settled mass, and potentially increase settled volumes. Any of these factors may affect the ability of the system to reach discharge limits within a reasonable time period.

Our objective was to determine the effect of sulfate to iron molar ratio and final treatment $\mathrm{pH}$ on the settling behavior of simulated, actively-treated acid mine drainage floc. Sodium hydroxide and ammonium hydroxide were used as the neutralizing bases to investigate the effects of the accompanying neutralization cation, and to avoid the complications of dispensing the solid bases $\mathrm{Na}_{2} \mathrm{CO}_{3}, \mathrm{CaCO}_{3}, \mathrm{Ca}(\mathrm{OH})_{2}$ or $\mathrm{CaO}$, and the precipitation of $\mathrm{CaSO}_{4}$. The effect of suspended solids concentration was determined, more specifically, within the sodium hydroxide system. These factors all have the potential to affect the physicochemical properties of iron and AMD precipitates, resulting in a significant effect on the settling behavior of actively-treated AMD floc. Settling properties are important because they influence the sizing of ponds to capture flocs, required residence time calculations, and the quality of the water being discharged to streams. This information also has the potential to alter the typical approach to acid mine drainage treatment. 


\section{Methods and Materials}

All initial solutions were 1.5 L in volume and comprised of $0.001 \mathrm{M} \mathrm{Fe}$ $\left(\mathrm{FeCl}_{3} \cdot 6 \mathrm{H}_{2} \mathrm{O}\right)$ and $0.000,0.0025$, or $0.0050 \mathrm{M} \mathrm{SO}_{4}\left(\mathrm{Na}_{2} \mathrm{SO}_{4}\right.$ or $\left.\left(\mathrm{NH}_{4}\right)_{2} \mathrm{SO}_{4}\right)$. All solutions were neutralized using small volumes of $1.0 \mathrm{~N} \mathrm{NaOH}$ or $\mathrm{NH}_{4} \mathrm{OH}$ using the same coordinating cation as the sulfate salt (Table 1) to near the desired pH value (Accumet ${ }^{\circledR}$ Model $15 \mathrm{pH}$ meter, Fisher Scientific). Neutralization continued by drop-wise addition of $0.1 \mathrm{~N}$ base until the exact $\mathrm{pH}$ of $7.0,8.0$ or 9.0 was obtained and remained constant for at least 5 seconds. The electrical conductivity of each neutralized solution was recorded (Markson Solution Analyzer, Model 4603). All suspensions were generated and remained on an insulated stir plate at constant speed until all subsequent procedures were completed to prevent settling and ensure representative aliquot collection. A $10 \mathrm{~mL}$ aliquot of each solution was taken from both the un-neutralized and neutralized states for iron determination by inductively coupled plasma (ICP) spectroscopy (Perkin Elmer Emission Spectrometer Plasma 400, Model P400) and sulfate concentration analysis by the turbidimetric method (Automated Ion Analyzer Omnion FIA+, QuickChem ${ }^{\circledR} 8000$ series). Samples taken after neutralization were filtered through Whatman 42 papers and acidified with nitric acid. However, a determination was made that the acid interfered with the sulfate analysis. So, unacidified samples were also taken. The centrifuge tubes were wrapped in parafilm and stored at $4^{\circ} \mathrm{C}$. Neutralization $\mathrm{pH}$ values contained three significant figures.

The dry weight of each floc type was determined by oven drying $20 \mathrm{~mL}$ of the neutralized solution in a pre-weighed aluminum dish to constant mass at $100^{\circ} \mathrm{C}$. The dishes were allowed to cool to room temperature before weighing (Mettler AE 100 Balance).

Settling rates were determined spectrophotometrically using plastic $1 \mathrm{~cm}$ path length cuvettes in a Hewlett Packard 8452A Diode Array Spectrophotometer (Agilent Laboratories, Palo Alto, CA). Imhoff Settling Cones were used to determine settled floc mass (dry mass of settled floc) and settled floc volumes (volume floc per volume of solution). Calibration curves were based on absorbance readings of 0.100 , 
Table 1. Composition of initial synthetic AMD and neutralizing solutions.

\begin{tabular}{|c|c|c|c|}
\hline Cation & Sulfate to Iron Molar Ratio & Initial Solution & Neutralizing Solution \\
\hline \multirow[t]{5}{*}{$\mathrm{Na}$} & $0: 1$ & $0.001 \mathrm{M} \mathrm{FeCl}_{3}$ & 1.0 and $0.1 \mathrm{M} \mathrm{NaOH}$ \\
\hline & $2.5: 1$ & $0.001 \mathrm{M} \mathrm{FeCl}_{3}$ & 1.0 and $0.1 \mathrm{M} \mathrm{NaOH}$ \\
\hline & & $0.0025 \mathrm{M} \mathrm{Na}_{2} \mathrm{SO}_{4}$ & \\
\hline & $5: 1$ & $0.001 \mathrm{M} \mathrm{FeCl}_{3}$ & 1.0 and $0.1 \mathrm{M} \mathrm{NaOH}$ \\
\hline & & $0.0050 \mathrm{M} \mathrm{Na}_{2} \mathrm{SO}_{4}$ & \\
\hline \multirow[t]{5}{*}{$\mathrm{NH}_{4}$} & $0: 1$ & $0.001 \mathrm{M} \mathrm{FeCl}_{3}$ & 1.0 and $0.1 \mathrm{M} \mathrm{NH}_{4} \mathrm{OH}$ \\
\hline & $2.5: 1$ & $0.001 \mathrm{M} \mathrm{FeCl}_{3}$ & 1.0 and $0.1 \mathrm{M} \mathrm{NH}_{4} \mathrm{OH}$ \\
\hline & & $0.0025 \mathrm{M}\left(\mathrm{NH}_{4}\right)_{2} \mathrm{SO}_{4}$ & \\
\hline & $5: 1$ & $0.001 \mathrm{M} \mathrm{FeCl}_{3}$ & 1.0 and $0.1 \mathrm{M} \mathrm{NH}_{4} \mathrm{OH}$ \\
\hline & & $0.0050 \mathrm{M}\left(\mathrm{NH}_{4}\right)_{2} \mathrm{SO}_{4}$ & \\
\hline
\end{tabular}

$0.250,0.500,1.000,1.500,2.000,2.500$, and $3.000 \mathrm{ml}$ of titrated suspension, of known solids concentration, in $3.000 \mathrm{~mL}$ total volume at $560 \mathrm{~nm}$. Required volumes were created by mixing suspension with filtrate (Whatman 42). A separate calibration curve to calculate floc concentration from absorbance measurements was made for each replicate.

The settling solutions were analyzed in cuvettes at concentrations of $400 \mathrm{mg}$ floc $\mathrm{L}^{-1}$ solution (sodium system) or $275 \mathrm{mg}$ floc $\mathrm{L}^{-1}$ solution (sodium and ammonium systems). In order to ensure that each settling suspension had similar initial floc concentrations, the aliquot was diluted with supernatant so that the initial absorbance of each suspension was constant. Before each settling experiment, the spectrophotometer was zeroed using neutralized suspension filtrate (Whatman 42). Cuvettes were covered with parafilm and mixed by inversion. Absorbance was recorded at $560 \mathrm{~nm}$ every $20 \mathrm{~s}$ for 1 hour. Cuvette suspensions were not allowed to settle before being placed in the spectrophotometer.

One (1) liter of neutralized solution was allowed to settle in a Nalgene ${ }^{\circledR}$ Imhoff Settling Cone based on Eaton et al. (1995). Settled floc volumes were recorded after 1 hour. Supernatant was decanted and the remaining suspension filtered through Whatman 
42 paper filters. To determine settled floc mass, filtered floc was rinsed with several volumes of distilled deionized water and transferred to weighed polystyrene weighing boats. The floc was air-dried in a hood until it appeared mostly dry. Drying was completed in an oven at $60^{\circ} \mathrm{C}$ and the mass of the floc and dish recorded.

The zero point of charge was determined by a cation-anion exchange method modified from Zelazny and Vanwormhoudt (1996) and Sumner and Miller (1996). Floc was concentrated by centrifugation (IEC Model K Centrifuge) from $500 \mathrm{~mL}$ of suspension and transferred to a weighed $50 \mathrm{~mL}$ polypropylene centrifuge tube. Remaining solution was carefully removed from each tube by pipette after centrifugation until clear in a Sorvall Superspeed RC2-B Automatic Refrigerated Centrifuge. Twenty $\mathrm{mL} 0.2 \mathrm{M} \mathrm{CaCl}_{2}$ was added to each tube. The tubes were shaken for 5 minutes, centrifuged, and the supernatants decanted. Another $20 \mathrm{~mL}$ adjusted to the desired $\mathrm{pH}$ with saturated $\mathrm{Ca}(\mathrm{OH})_{2}$ or $\mathrm{HCl}$ was then added. The desired $\mathrm{pH}$ matched the $\mathrm{pH}$ at which the solution was neutralized. The tube suspensions were allowed to equilibrate at room temperature on a reciprocal shaker (Eberbach Corporation) for 10 hours, after which they were centrifuged and the supernatants discarded. Twenty $\mathrm{mL} 0.025 \mathrm{M} \mathrm{CaCl}_{2}$ solution adjusted to the same desired $\mathrm{pH}$ was then added to each tube. The tubes were shaken 5 minutes, centrifuged, and decanted. This sequence was repeated two more times, saving the last wash for determination of $\mathrm{Ca}$ and $\mathrm{Cl}$. The $\mathrm{pH}$ of the supernatants was measured and each tube reweighed with its contents to permit correction for entrained solution. Tube contents were washed 3 times with $20 \mathrm{~mL} 1.0 \mathrm{M} \mathrm{KNO}_{3}$, shaken 5 minutes, and centrifuged. Supernatants were combined in a $100 \mathrm{~mL}$ volumetric flask and brought to volume. Flasks were mixed by inversion and filtered with Whatman 42 filter paper. Ca concentrations were determined by ICP (Perkin Elmer Emission Spectrometer Plasma 400, Model P400) and Cl by flow injection analysis (Automated Ion Analyzer Omnion FIA+, QuickChem ${ }^{\circledR} 8000$ series). The tubes with precipitates were oven-dried at $60^{\circ} \mathrm{C}$ to determine the dry mass of precipitate.

The experimental design was a 2 (cation) $\times 3$ (sulfate to iron molarratio) $\times 3(\mathrm{pH})$ factorial with three replications. Imhoff cone results (settled mass and volume) were analyzed by analysis of variance using PROC GLM (SAS Inst., Cary, NC). The main effects of cation, sulfate to iron molar ratio and $\mathrm{pH}$ entered the model as class variables, and all 
possible interactions were considered. In the sodium system, solids concentration replaced cation as a class variable. Again, all possible interactions were investigated. To determine PZNC, separate regression equations for CEC and AEC were determined for each cation using PROC GLM with a full model that accounted for $\mathrm{pH}$, sulfate to iron molar ratio and $\mathrm{pH}^{*}$ sulfate to iron molar ratio interaction. Only significant terms $(\alpha=0.05)$ were included in the final equations. Surface charge for each cation and sulfate to iron molar ratio combination was determined from these equations. PZNC was determined by setting the CEC equation equal to the AEC equation and solving for $\mathrm{pH}$. All time-dependent floc concentrations were expressed as the fraction of the initial concentration of $275 \mathrm{mg} \mathrm{L}^{-1}\left(\mathrm{C}_{0}\right)$ or $400 \mathrm{mg} \mathrm{L}^{-1}\left(\mathrm{C}_{0}\right)$. In the phase rate analyses, the graph of each replicate was reviewed visually to select data points representative of the end of phases 1 and 2 and the beginning of phase 4. Again, an analysis of variance model was developed with the class variables cation (or solids), sulfate to iron molar ratio, and $\mathrm{pH}$, and all possible interactions (PROC GLM). These models were used to determine differences between treatments in mean settling times, final suspended solids concentrations, and settling rates (slope) within each phase as appropriate. Phase 3 data are not reported because sudden spikes in this portion of the settling curves prohibited determination of a representative slope. For all analysis of variance, main effect and interaction means and standard errors were determined using the MEANS option in PROC GLM. Means were compared using orthogonal linear contrasts. Settling generally followed the four phase pattern described by Lee et al. (1983): reflocculation, or lag, (phase 1), initial settling (phase 2), transition (phase 3), and compression (phase 4) (Figure 3). When the lag phase was not detected, the data point was treated as a missing value in the data set.

While individual phases of the settling process are essential to a full understanding of the scientific behavior of these systems, we recognize that facilities will generally focus on a pond residence time and meeting the allowable discharge limits in practice. For this reason, settling systems were evaluated with respect to their ability to meet discharge limits and their properties after one hour's time.

For the settling analysis reflecting ability to reach a discharge limit of $70 \mathrm{mg} \mathrm{L}^{-1}$ total suspended solids (TSS), settling time was defined as the time required to reach that limit. Data were smoothed using a moving average of three measurements. For settling 
curves that did not reach the discharge limit, the settling time was set to the maximum settling time of 3600s. Initial settling rate was determined from the initial $(t<300 \mathrm{~s})$, linear portion of the settling curves. A linear regression model was fit to each experimental unit (cation $\mathrm{x}$ sulfate to iron molar ratio $\mathrm{x} \mathrm{pH} \times$ rep $=54$ total) to determine the initial and final slope of the settling curve. These calculated slopes were then used in an analysis of variance as the dependent variable in a model that included cation, sulfate to iron molar ratio, $\mathrm{pH}$ and all interactions as class variables (PROC GLM). For all analysis of variance, main effect and interactions means and standard errors were determined using the MEANS option in PROC GLM. Means were compared using orthogonal linear contrasts. 


\section{Results}

PZNC

Averaged across all sulfate to iron molar ratios, PZNC was higher in the ammonium system (7.9) than in the sodium system (7.6). Adding sulfate increased the PZNC from $7.7(0: 1)$ to $7.9(2.5: 1)$ or $8.1(5: 1)$ in the ammonium system and decreased PZNC from $7.8(0: 1)$ to $7.5(2.5: 1)$ or $7.4(5: 1)$ in the sodium system. However, these differences were within the experimental error of the method, and the experiment-wise average PZNC of 7.7 (all cations, all sulfate to iron molar ratios) was used as the PZNC for all floc formed.

\section{Phase 1 Settling Properties}

\section{$\underline{\text { Settling Times }}$}

Significant model terms for phase 1 settling times were cation, sulfate to iron molar ratio, $\mathrm{pH}$, sulfate to iron molar ratio* $\mathrm{pH}$ and cation*sulfate to iron molar ratio* $\mathrm{pH}$ (Table 2). Phase 1 settling times were more than doubled in the ammonium system over the sodium system (Table 3). There was a significant quadratic trend with respect to sulfate to iron molar ratio, exhibiting a maximum settling time at the 2.5:1 ratio (Tables 2 and 3). A significant quadratic trend is also observed for $\mathrm{pH}$ with a maximum time at $\mathrm{pH}$ 8 (Tables 2 and 3). The two sulfate systems within any given $\mathrm{pH}$ were always significantly different from each other, the 2.5:1 sulfate to iron molar ratio consistently yielding longer times (Figure 4). Across $\mathrm{pH}$ values, the presence of sulfate at $\mathrm{pH} 8$ resulted in longer times (Figure 4).

\section{Final Suspended Solids Concentration}

Significant model terms for suspended solids concentration at the end of phase 1 were cation, sulfate to iron molar ratio, $\mathrm{pH}$, sulfate to iron molar ratio*pH and cation*sulfate to iron molar ratio*pH (Table 2). Suspended solids concentrations were higher in the sodium system (Table 3). Orthogonal linear contrasts revealed a significant quadratic trend with respect to sulfate to iron molar ratio with a minimum at the $2.5: 1$ ratio (Tables 2 and 3). Contrasts also showed a significant quadratic relationship for $\mathrm{pH}$ 
Table 2. Type III sums of squares and significance levels of main effects, interactions and orthogonal linear contrasts for Phase 1 duration time, final suspended solids concentration, and settling rate when comparing treatment chemical systems.

\begin{tabular}{|c|c|c|c|c|c|c|}
\hline \multirow[b]{2}{*}{ Source } & \multicolumn{2}{|c|}{ Settling Time } & \multicolumn{2}{|c|}{ Suspended Solids Concentration } & \multicolumn{2}{|c|}{ Settling Rate } \\
\hline & $\mathrm{SS}^{\mathrm{a}} \times 10^{-5}$ & $\operatorname{Pr}>F$ & $\mathrm{SS}^{\mathrm{a}} \times 10^{2}$ & $\operatorname{Pr}>F$ & $\mathrm{SS}^{\mathrm{a}} \times 10^{7}$ & $\operatorname{Pr}>\mathrm{F}$ \\
\hline Cation & 2.70 & $<0.0001$ & 3.49 & $<0.0001$ & na & na \\
\hline Sulfate to Iron Molar Ratio & 2.67 & $<0.0001$ & 4.74 & $<0.0001$ & 7.84 & 0.0056 \\
\hline Cation*Sulfate to Iron Molar Ratio & na & na & na & na & na & na \\
\hline $\mathrm{pH}$ & 2.86 & $<0.0001$ & 1.43 & 0.0105 & na & na \\
\hline Cation*pH & na & na & na & na & na & na \\
\hline Sulfate to Iron Molar Ratio*pH & 0.84 & 0.0137 & 1.70 & 0.0278 & na & na \\
\hline Cation*Sulfate to Iron Molar Ratio*pH & 1.20 & 0.0238 & 3.07 & 0.0167 & na & na \\
\hline \multicolumn{7}{|l|}{ Contrasts } \\
\hline \multicolumn{7}{|l|}{ Sulfate to Iron Molar Ratio } \\
\hline Linear & 0.03 & 0.4611 & 1.78 & 0.0010 & 7.51 & 0.0017 \\
\hline Quadratic & 2.64 & $<0.0001$ & 2.96 & $<0.0001$ & 0.21 & 0.5751 \\
\hline \multicolumn{7}{|l|}{$\mathrm{pH}$} \\
\hline Linear & 0.04 & 0.4354 & 0.05 & 0.5707 & na & na \\
\hline Quadratic & 2.82 & $<0.0001$ & 1.39 & 0.0031 & na & na \\
\hline
\end{tabular}

a: Type III Sums of Squares for model main effects and interactions; Contrast Sums of Squares for linear contrasts 
Table 3. Cation, sulfate to iron molar ratio and $\mathrm{pH}$ effects on the average Phase 1 duration time, final suspended solids concentration, and settling rate when comparing treatment chemical systems.

\begin{tabular}{lcccc}
\hline Parameter & Level & Settling Time $^{\mathrm{a}}$ & $\begin{array}{c}\text { Solids } \\
\text { Concentration }^{\mathrm{b}}\end{array}$ & Settling Rate $^{\mathrm{c}}$ \\
\hline \multirow{3}{*}{ Cation } & $\mathrm{Na}$ & 113 & $9.6 \times 10^{-1}$ & $\mathrm{~s}^{-1}$ \\
& $\mathrm{NH}_{4}$ & 254 & $9.1 \times 10^{-1}$ & na \\
& & & & na \\
Sulfate to Iron Molar Ratio & $0: 1$ & 124 & $9.3 \times 10^{-1}$ & $-5.1 \times 10^{-4}$ \\
& $2.5: 1$ & 282 & $9.0 \times 10^{-1}$ & $-3.2 \times 10^{-4}$ \\
& $5: 1$ & 143 & $9.8 \times 10^{-1}$ & $-1.9 \times 10^{-4}$ \\
$\mathrm{pH}$ & 7 & 142 & $9.5 \times 10^{-1}$ & na \\
& 8 & 286 & $9.1 \times 10^{-1}$ & na \\
& 9 & 122 & $9.5 \times 10^{-1}$ & na \\
\hline
\end{tabular}

a: Mean square error $=5.79 \times 10^{3}, \mathrm{df}=36$.

b: Mean square error $=1.38 \times 10^{-3}, \mathrm{df}=36$.

c: Mean square error $=6.64 \times 10^{-8}, \mathrm{df}=40$.

(Table 2). The minimum final phase 1 suspended solids concentration was at $\mathrm{pH} 8$ (Table 3) consistent with a PZNC near $\mathrm{pH} 8$. However, this average is highly affected by the sulfate to iron molar ratio* $\mathrm{pH}$ interaction. Taken across $\mathrm{pH}$ values, only the $2.5: 1$ sulfate to iron molar ratio system revealed a significant difference; the final suspended solids concentration being lower at $\mathrm{pH} 8$ (Figure 5).

\section{$\underline{\text { Settling Rates }}$}

The only significant model term for settling rate in phase 1 was sulfate to iron molar ratio (Table 2). There was a significant linear trend to decrease settling rate with an increase in sulfate to iron molar ratio (Tables 2 and 3).

\section{Phase 2 Settling Properties}

\section{$\underline{\text { Settling Times }}$}

Phase 2 settling time had significant model effects of sulfate to iron molar ratio, cation*sulfate to iron molar ratio, $\mathrm{pH}$, sulfate to iron molar ratio*pH and cation*sulfate to iron molar ratio* $\mathrm{pH}$ (Table 4). Contrasts for both sulfate to iron molar ratio and $\mathrm{pH}$ exhibited a quadratic trend with maxima of 2.5:1 and $\mathrm{pH} 8$, respectively (Tables 4 and 5). 


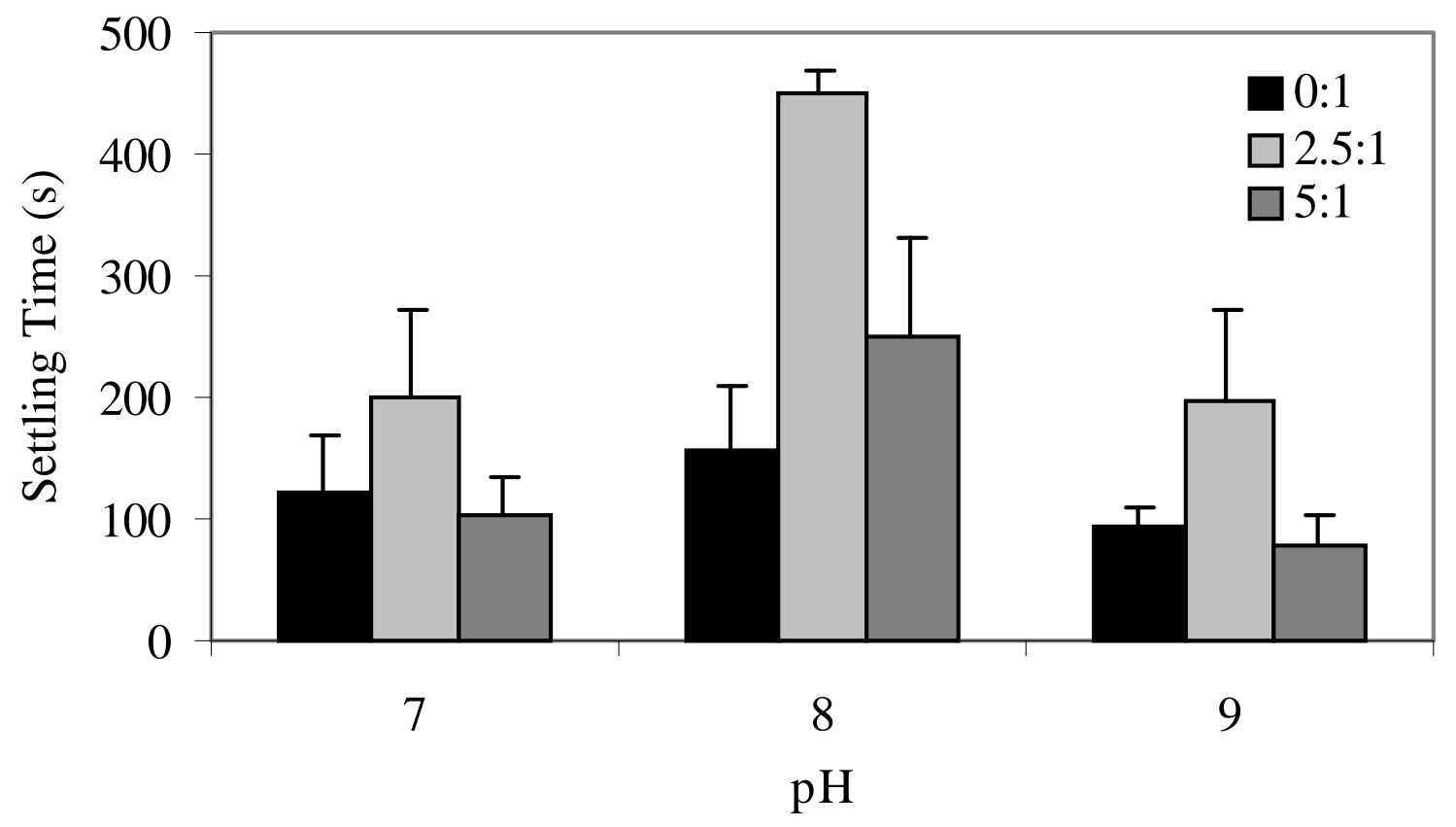

Figure 4. Average settling time (s) for the sodium and ammonium flocs at the end of phase 1 as affected by $\mathrm{pH}$ and sulfate to iron molar ratio. Error bars represent standard deviation calculated for each subset of treatment interactions presented. $\mathrm{df}=5$ 


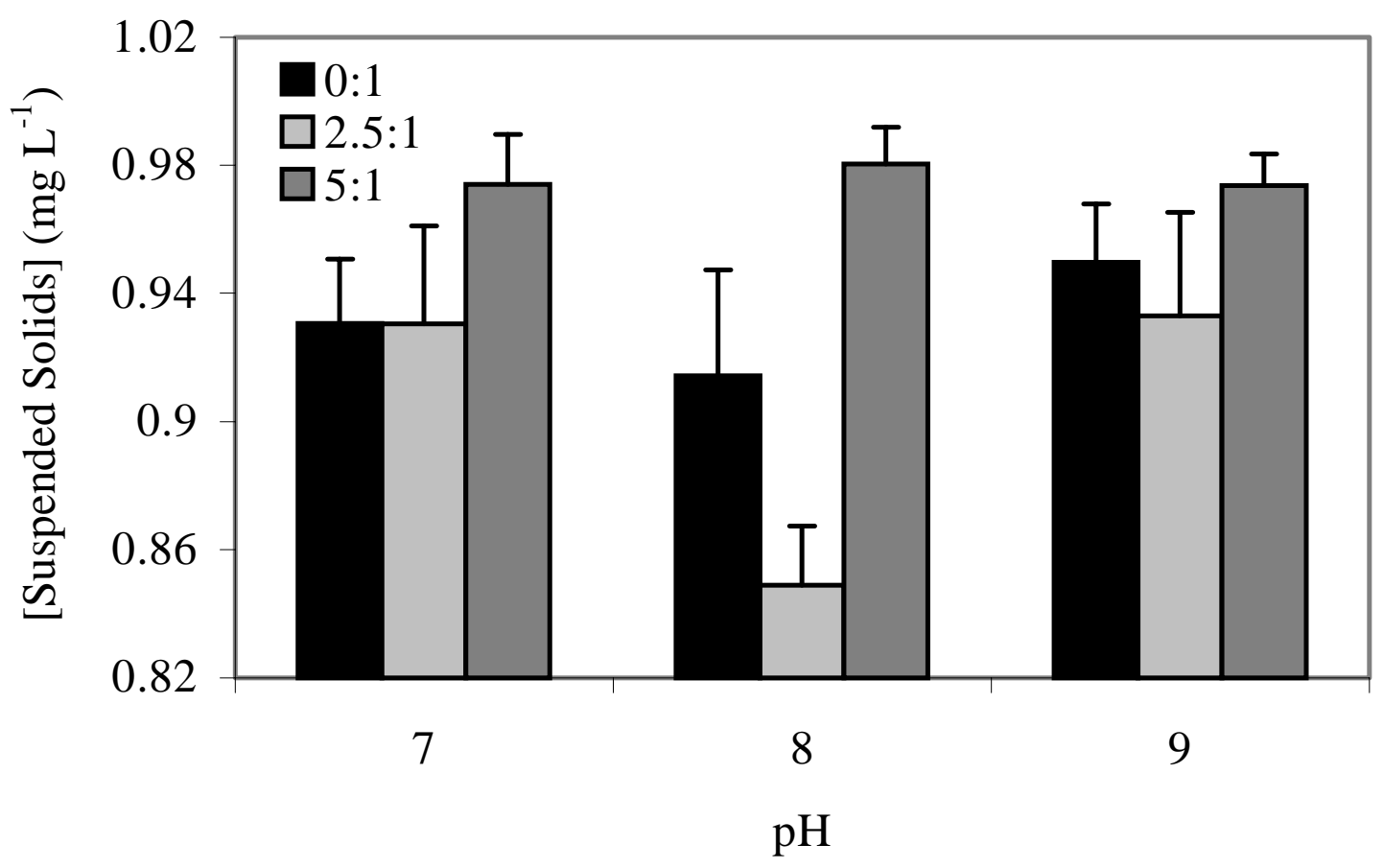

Figure 5. Average suspended solids concentration $\left(\mathrm{mg} \mathrm{L}^{-1}\right)$ at the end of phase 1 as affected by $\mathrm{pH}$ and sulfate to iron molar ratio. Error bars represent standard deviation calculated for each subset of treatment interactions presented. $\mathrm{df}=5$ 
Table 4. Type III sums of squares and significance levels of main effects, interactions and orthogonal linear contrasts for Phase 2 duration time, final suspended solids concentration, and settling rate when comparing treatment chemical systems.

\begin{tabular}{|c|c|c|c|c|c|c|}
\hline \multirow[b]{2}{*}{ Source } & \multicolumn{2}{|c|}{ Settling Time } & \multicolumn{2}{|c|}{ Suspended Solids Concentration } & \multicolumn{2}{|c|}{ Settling Rate } \\
\hline & $\mathrm{SS}^{\mathrm{a}} \times 10^{-5}$ & $\operatorname{Pr}>\mathrm{F}$ & $\mathrm{SS}^{\mathrm{a}} \times 10^{1}$ & $\operatorname{Pr}>\mathrm{F}$ & $\mathrm{SS}^{\mathrm{a}} \times 10^{6}$ & $\operatorname{Pr}>\mathrm{F}$ \\
\hline Cation & na & na & na & na & 5.24 & 0.0001 \\
\hline Sulfate to Iron Molar Ratio & 0.88 & 0.0025 & 8.68 & $<0.0001$ & 7.45 & $<0.0001$ \\
\hline Cation*Sulfate to Iron Molar Ratio & 2.20 & $<0.0001$ & 1.92 & $<0.0001$ & na & na \\
\hline $\mathrm{pH}$ & 2.27 & $<0.0001$ & na & na & na & na \\
\hline Cation*pH & na & na & na & na & na & na \\
\hline Sulfate to Iron Molar Ratio*pH & 1.21 & 0.0029 & 1.15 & 0.0083 & 5.73 & 0.0024 \\
\hline Cation*Sulfate to Iron Molar Ratio*pH & 3.75 & $<0.0001$ & 1.00 & 0.0168 & na & na \\
\hline \multicolumn{7}{|l|}{ Contrasts } \\
\hline \multicolumn{7}{|l|}{ Sulfate to Iron Molar Ratio } \\
\hline Linear & 0.09 & 0.2420 & 8.29 & $<0.0001$ & 7.41 & $<0.0001$ \\
\hline Quadratic & 0.79 & 0.0010 & 0.39 & 0.0120 & 0.03 & 0.7296 \\
\hline \multicolumn{7}{|l|}{$\mathrm{pH}$} \\
\hline Linear & 0.92 & 0.0004 & na & na & na & na \\
\hline Quadratic & 1.35 & $<0.0001$ & na & na & na & na \\
\hline
\end{tabular}

a: Type III Sums of Squares for model main effects and interactions; Contrast Sums of Squares for linear contrasts 
Table 5. Cation, sulfate to iron molar ratio and $\mathrm{pH}$ effects on the average Phase 2 duration time, final suspended solids concentration, and settling rate when comparing treatment chemical systems.

\begin{tabular}{lcccc}
\hline Parameter & Level & Settling Time $^{\mathrm{a}}$ & $\begin{array}{c}\text { Solids } \\
\text { Concentration }^{\mathrm{b}}\end{array}$ & Settling Rate $^{\mathrm{c}}$ \\
\hline \multirow{2}{*}{ Cation } & $\mathrm{Na}$ & $\mathrm{s}$ & $\mathrm{mg} \mathrm{L}$ & $\mathrm{s}^{-1}$ \\
& $\mathrm{NH}_{4}$ & $\mathrm{na}$ & $\mathrm{na}$ & $-1.3 \times 10^{-3}$ \\
Sulfate to Iron Molar Ratio & $0: 1$ & 393 & $\mathrm{na}$ & $-2.0 \times 10^{-3}$ \\
& $2.5: 1$ & 490 & $6.1 \times 10^{-1}$ & $-2.1 \times 10^{-3}$ \\
& $5: 1$ & 424 & $7.1 \times 10^{-1}$ & $-1.6 \times 10^{-3}$ \\
$\mathrm{pH}$ & 7 & 451 & $\mathrm{na}$ & \\
& 8 & 507 & $\mathrm{na}$ & $\mathrm{na}$ \\
& 9 & 350 & $\mathrm{na}$ & $\mathrm{na}$ \\
\hline
\end{tabular}

a: Mean square error $=6.16 \times 10^{3}, \mathrm{df}=36$.

b: Mean square error $=5.51 \times 10^{-3}, \mathrm{df}=36$.

c: Mean square error $=2.8 \times 10^{-7}, \mathrm{df}=36$.

The cation*sulfate to iron molar ratio interaction showed a cross-over type relationship with mean times higher in the sodium system at $\mathrm{pH} 7$ and 9 , and higher in the ammonium system at $\mathrm{pH}$ 8. The significant cation*sulfate to iron molar ratio interaction was due to the longer settling time in the ammonium system at sulfate to iron molar ratio 2.5:1 (Figure 6). The significant $\mathrm{pH}^{*}$ sulfate to iron molar ratio interaction was principally due to the effect of sulfate to iron molar ratio at $\mathrm{pH} 7$ (Figure 7).

\section{Final Suspended Solids Concentration}

The significant model terms for suspended solids concentration at the end of phase 2 were sulfate to iron molar ratio, cation *sulfate to iron molar ratio, sulfate to iron molar ratio*pH and cation*sulfate to iron molar ratio*pH (Table 4). A significant quadratic relationship was identified for sulfate to iron molar ratio, with the maximum near 5:1 (Tables 4 and 5). Type III sums of squares showed sulfate to iron molar ratio to be the single most important effect (Table 4). Within the sodium system, final suspended solids concentrations with sulfate were consistently higher than without sulfate (Figure 8). Within the ammonium system, the 5:1 sulfate to iron molar ratio yielded a greater final suspended solids concentration than the 2.5:1 ratio (Figure 8). It is possible that both 


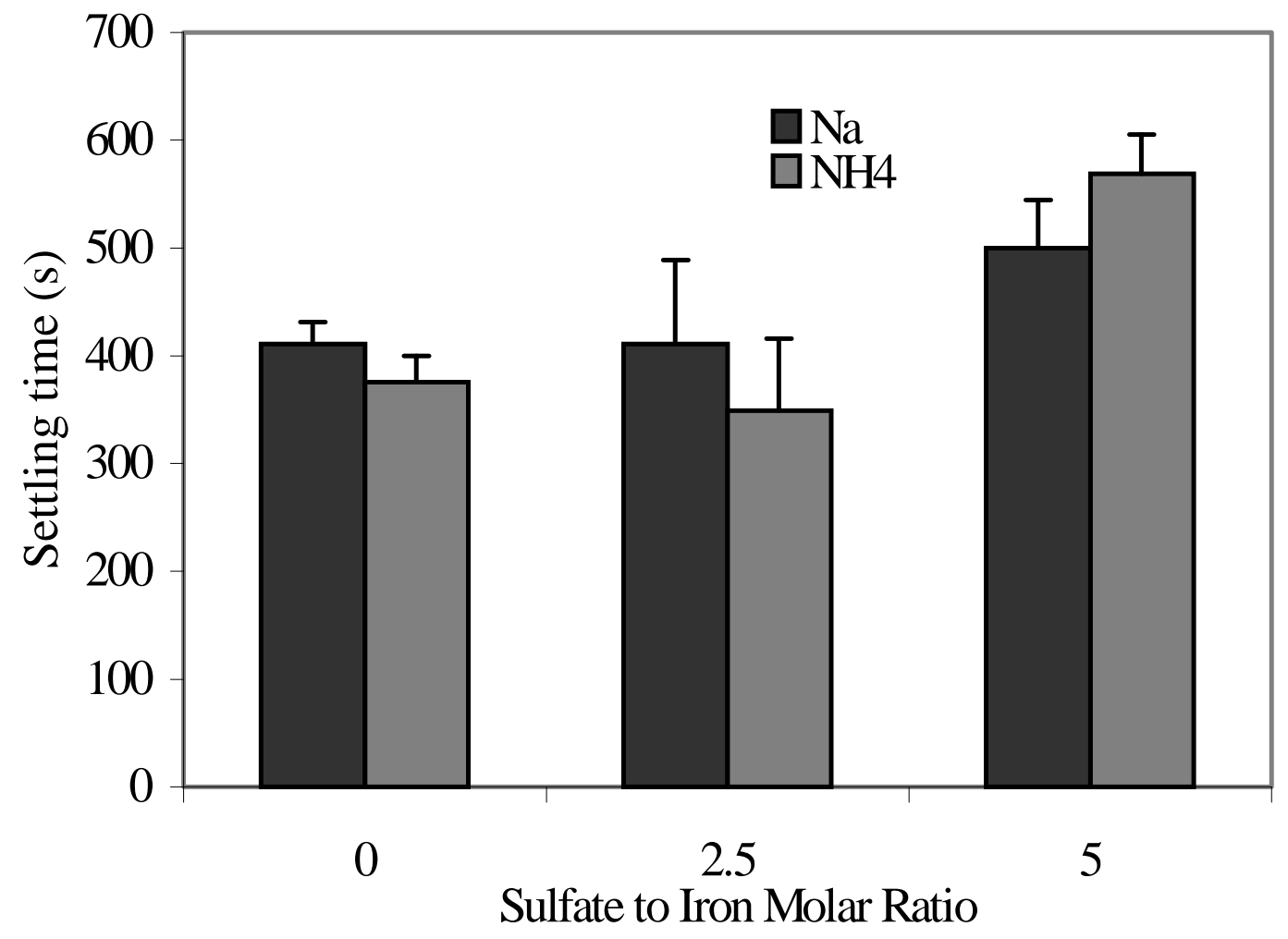

Figure 6. Average settling time (s) at the end of Phase 2 as affected by treatment cation and sulfate to iron molar ratio. Error bars represent standard deviation calculated for each subset of treatment interactions presented. $\mathrm{df}=8$ 


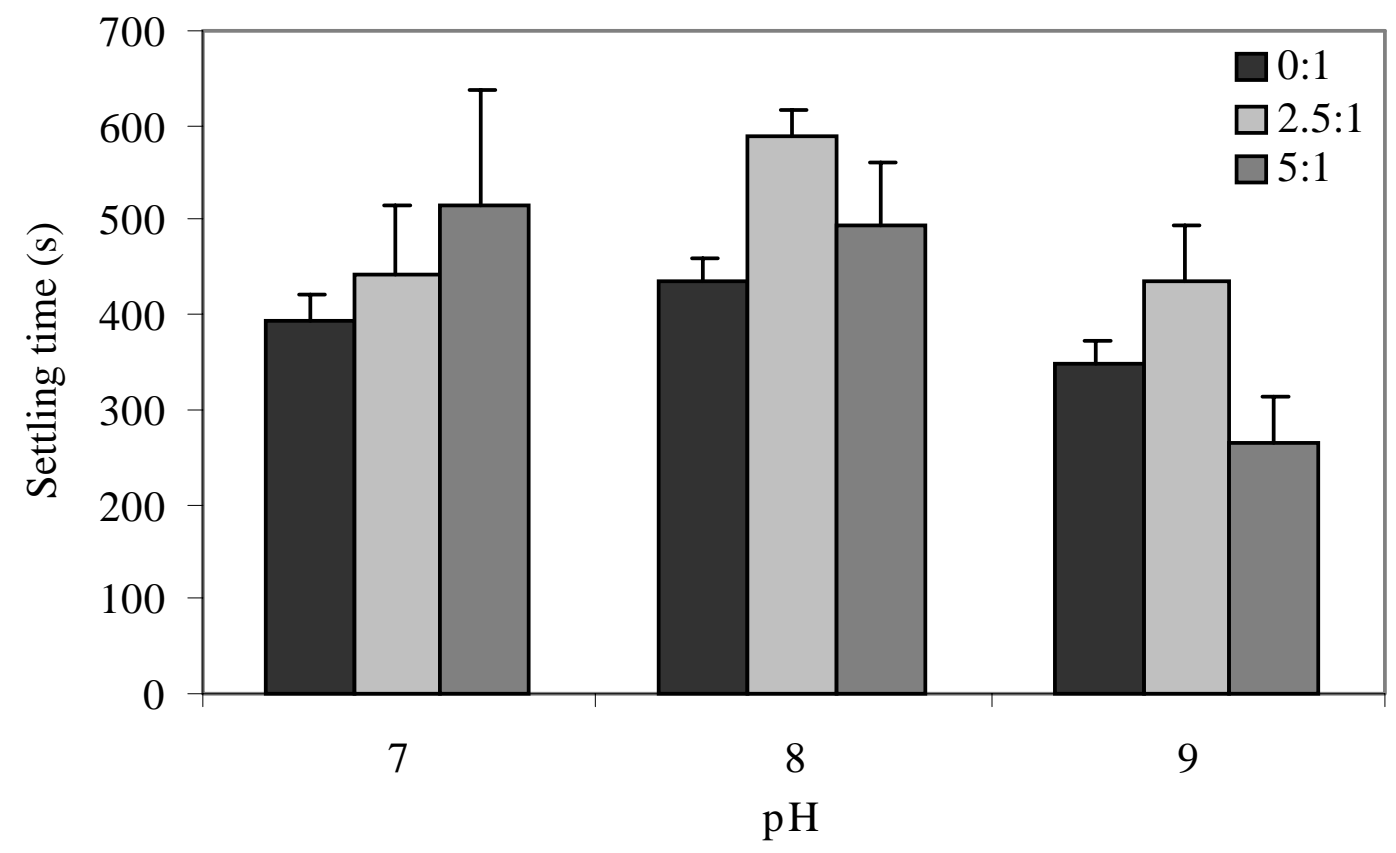

Figure 7. Average settling time at the end of Phase 2 as affected by $\mathrm{pH}$ and sulfate to iron molar ratio. Error bars represent standard deviation calculated for each subset of treatment interactions presented. $\mathrm{df}=5$ 


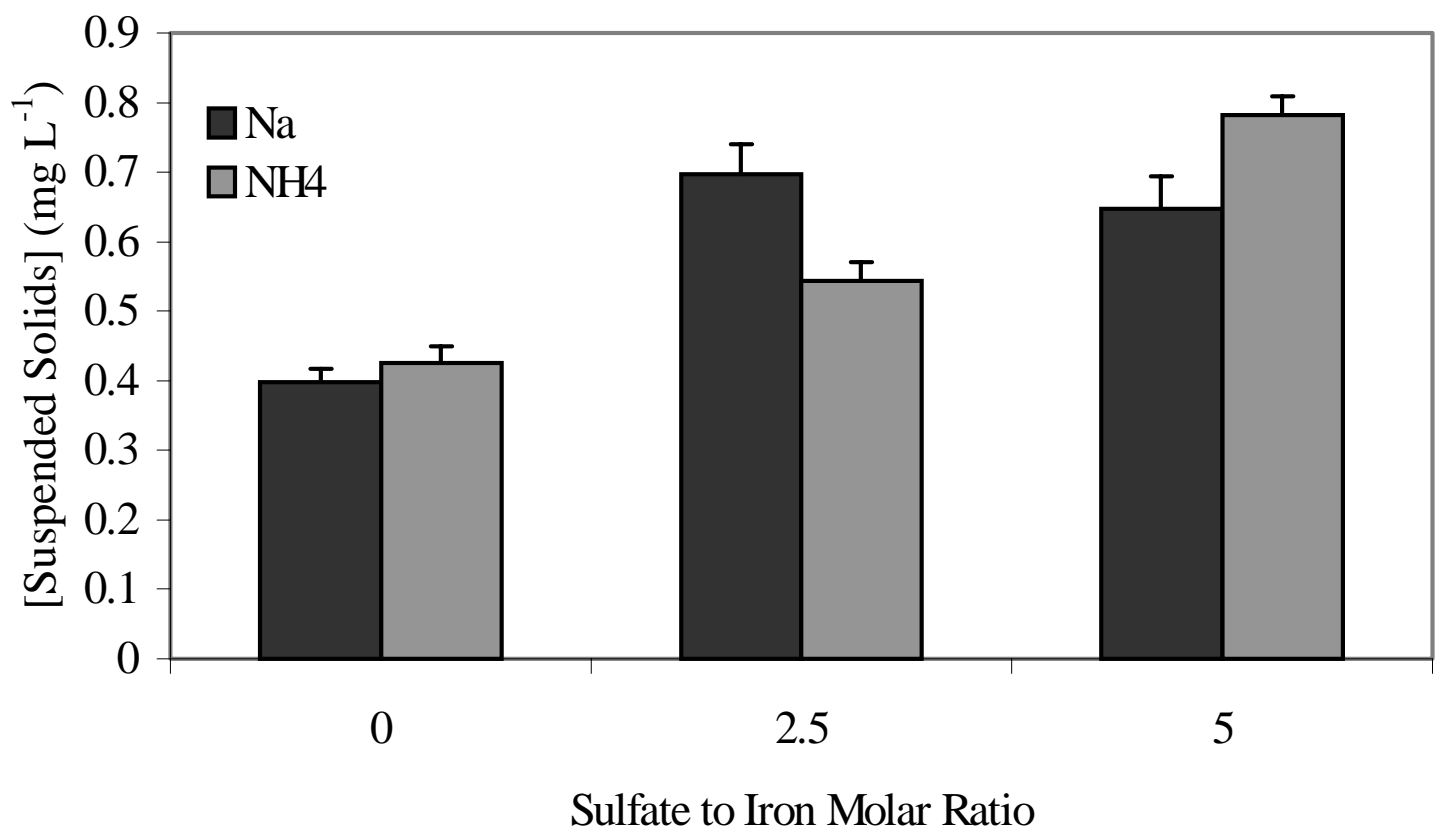

Figure 8. Average final suspended solids concentration in Phase 2 as affected by treatment cation and sulfate to iron molar ratio. Error bars represent standard deviation calculated for each subset of treatment interactions presented. $\mathrm{df}=8$ 
of these sulfate to iron molar ratio combinations would result in a greater final suspended solids concentration than would occur without sulfate. However the degree of error in the 0:1 ammonium system prevents us from making such a definitive conclusion (Figure 8). The presence of sulfate in the system consistently resulted in greater final suspended solids concentrations across all $\mathrm{pH}$ values (Figure 9). At $\mathrm{pH} \mathrm{8,} \mathrm{final} \mathrm{suspended} \mathrm{solids}$ concentration increased with increasing sulfate to iron molar ratio (Figure 9).

\section{$\underline{\text { Settling Rates }}$}

Significant model terms for phase 2 settling rates were cation, sulfate to iron molar ratio and sulfate to iron molar ratio* $\mathrm{pH}$ (Table 4). The mean settling rate was faster in the ammonium system than in the sodium (Table 5). A significant linear trend to decrease settling rate with increasing sulfate to iron molar ratio was noted (Tables 4 and 5 ) as in previous sections. However, at $\mathrm{pH} 8$, the settling rate was only significantly slower in the 5:1 sulfate to iron molar ratio system (Figure 10).

\section{Phase 4 Settling Rates}

The only significant effect for final settling rates in the sodium and ammonium systems was sulfate to iron molar ratio (Table 6). A significant quadratic trend exhibited a maximum near sulfate to iron molar ratio 5:1 (Tables 6 and 7).

\section{Effect of Solids Concentration on Phase 1 Settling Properties}

In comparing different initial suspended solids concentrations within the sodium system, the significant model terms for phase 1 settling time were sulfate to iron molar ratio, $\mathrm{pH}$, solids* $\mathrm{pH}$, sulfate to iron molar ratio* $\mathrm{pH}$ and solids*sulfate to iron molar ratio*pH (Tables 8 and 9). The significant solids*pH interaction is due to the effect at $\mathrm{pH}$ 8 (Figure 11). Final phase 1 suspended solids concentration in the sodium system was controlled by the model effects of sulfate to iron molar ratio, sulfate to iron molar ratio* $\mathrm{pH}$ and solids*sulfate to iron molar ratio*pH (Table 8). Phase 1 settling rates in the sodium system were controlled by the sulfate to iron molar ratio model effect (Table 8). 


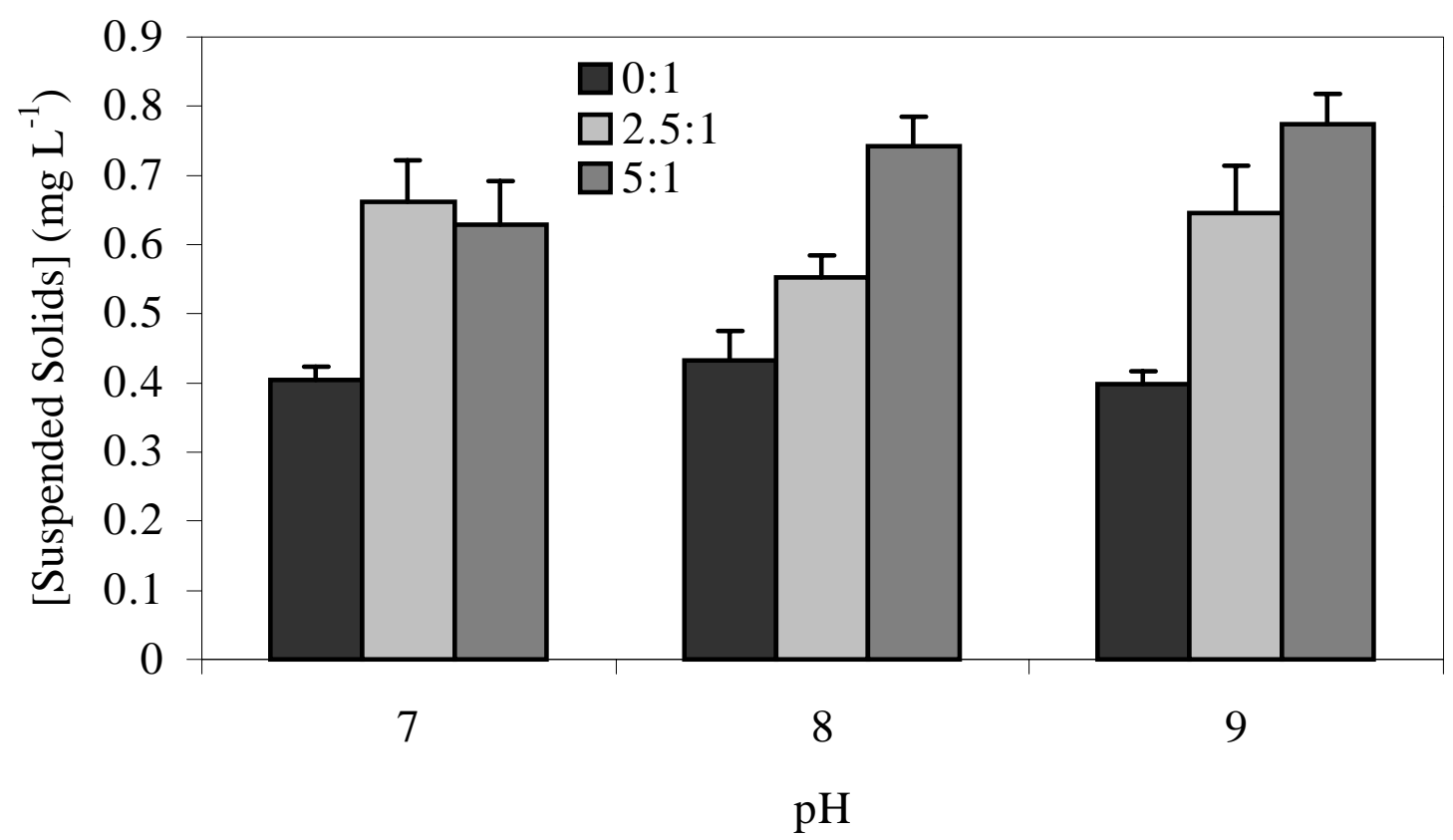

Figure 9. Average final suspended solids concentration for Phase 2 as affected by $\mathrm{pH}$ and sulfate to iron molar ratio. Error bars represent standard deviation calculated for each subset of treatment interactions presented. $\mathrm{df}=5$ 


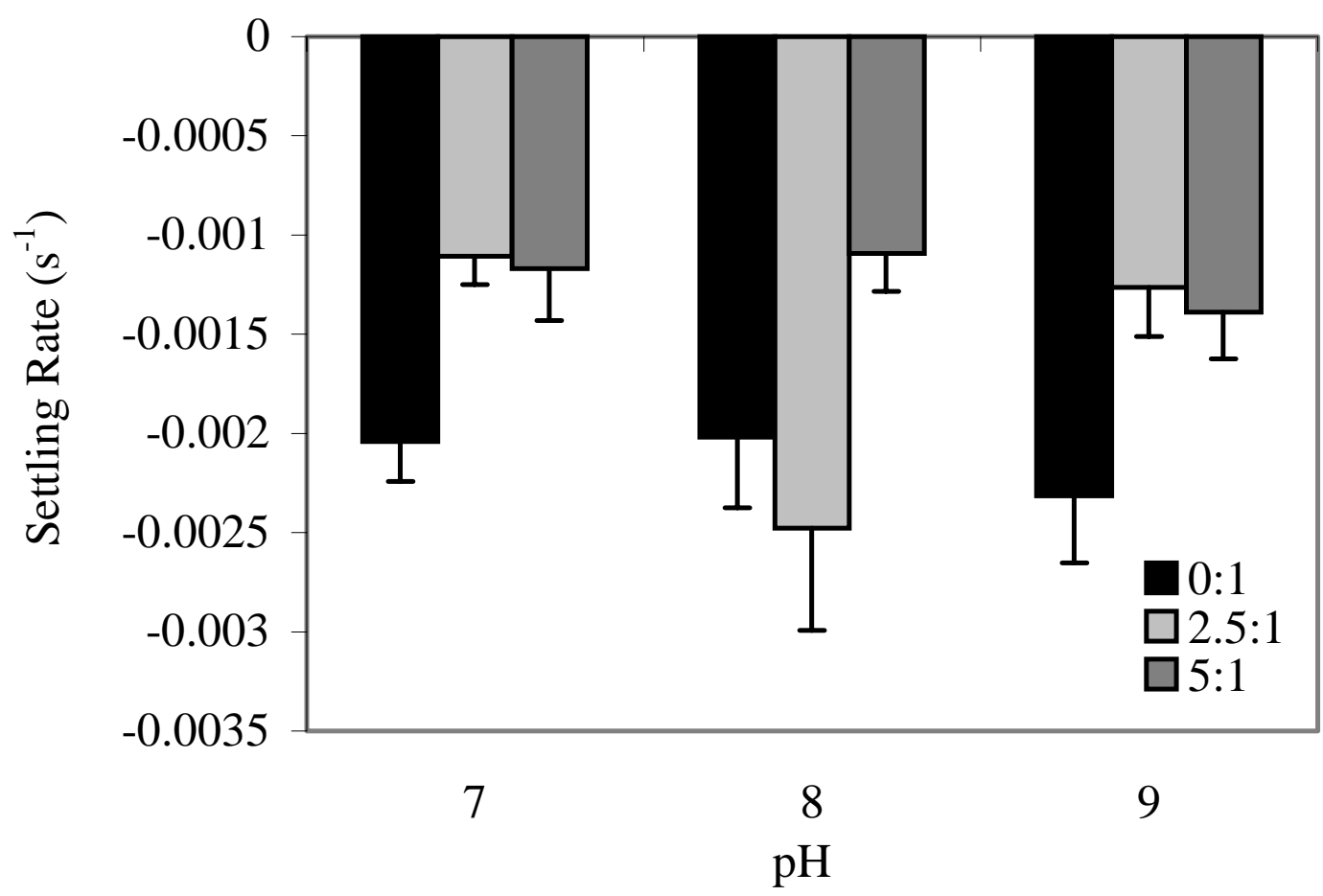

Figure 10. Average settling rate for Phase 2 as affected by $\mathrm{pH}$ and sulfate to iron molar ratio. Error bars represent standard deviation calculated for each subset of treatment interactions presented. $\mathrm{df}=5$ 
Table 6. Type III sums of squares and significance levels of main effects, interactions and orthogonal linear contrasts for Phase 4 settling rate when comparing treatment chemical systems.

\begin{tabular}{lcc}
\hline & \multicolumn{2}{c}{ Settling Rate } \\
\cline { 2 - 3 } Source & $\mathrm{SS}^{\mathrm{a}} \times 10^{9}$ & $\mathrm{Pr}>\mathrm{F}$ \\
\hline Cation & na & na \\
Sulfate to Iron Molar Ratio & 10.6 & $<0.0001$ \\
Cation*Sulfate to Iron Molar Ratio & na & na \\
$\mathrm{pH}$ & na & na \\
Cation*pH & na & na \\
Sulfate to Iron Molar Ratio*pH & na & na \\
Cation*Sulfate to Iron Molar Ratio*pH & na & na \\
& & \\
Contrasts & & \\
\hline Sulfate to Iron Molar Ratio & & $<0.0001$ \\
$\quad$ Linear & 5.90 & $<0.0001$ \\
$\quad$ Quadratic & 4.72 & na \\
pH & & na \\
$\quad$ Linear & & na \\
$\quad$ Quadratic & na &
\end{tabular}

\section{Effect of Solids Concentration on Phase 2 Settling Properties}

The significant model effects for phase 2 settling time were sulfate to iron molar ratio, solids*sulfate to iron molar ratio and sulfate to iron molar ratio*pH (Table 10). In the higher initial suspended solids concentration system, sulfate extended the phase settling time, with the greatest effect at sulfate to iron molar ratio 5:1 (Figure 12). In the lower initial suspended solids system, only the 5:1 sulfate to iron molar ratio system was significantly different from no sulfate (Figure 12).

Phase 2 final suspended solids concentration in the sodium system was governed by the following model effects: solids, sulfate to iron molar ratio and solids*sulfate to iron molar ratio (Table 10). Mean final solids concentrations were higher in the $275 \mathrm{mg}$ $\mathrm{SS} \mathrm{L}^{-1}$ initial suspended solids system (Table 11). Final phase 2 suspended solids concentration increased in the presence of sulfate, regardless of initial experiment suspended solids concentration (Figure 13). However, the significant solids*sulfate 
Table 7. Cation, sulfate to iron molar ratio and $\mathrm{pH}$ effects on the average Phase 4 final suspended solids concentration and settling rate when comparing treatment chemical systems.

\begin{tabular}{lcc}
\hline Parameter & Level & Settling Rate $^{\mathrm{a}}$ \\
\hline \multirow{2}{*}{ Cation } & $\mathrm{Na}$ & $\mathrm{s}$ \\
& $\mathrm{NH}_{4}$ & na \\
& & na \\
Sulfate to Iron Molar Ratio & $0: 1$ & $-1.6 \times 10^{-5}$ \\
& $2.5: 1$ & $-4.2 \times 10^{-5}$ \\
& $5: 1$ & $-4.9 \times 10^{-5}$ \\
$\mathrm{pH}$ & 7 & na \\
& 8 & na \\
& 9 & na \\
\hline
\end{tabular}

a: Mean square error $=2.50 \times 10^{-10}, \mathrm{df}=36$.

to iron molar ratio interaction is due to the effect seen in the $2.5: 1$ sulfate to iron molar ratio (Figure 13). The samples with initial $275 \mathrm{mg} \mathrm{SS} \mathrm{L}^{-1}$ finished phase 2 with significantly greater suspended solids concentrations than those with initial $400 \mathrm{mg} \mathrm{SS} \mathrm{L}^{-}$ 1 at these ratios (Figure 13).

The significant model effects controlling phase 2 settling rates in the sodium system were solids, sulfate to iron molar ratio, solids*sulfate to iron molar ratio, and sulfate to iron molar ratio* $\mathrm{pH}$ (Table 10). Mean settling rates were faster in the $400 \mathrm{mg}$ $\mathrm{SS} \mathrm{L}^{-1}$ system (Table 11). The significant solids*sulfate to iron molar ratio interaction was due to the large effect in the 5:1 sulfate to iron molar ratio (Figure 14).

\section{Ability to Meet Discharge Criteria (70 $\left.\mathrm{mg} \mathrm{L}^{-1} \mathrm{TSS}\right)$}

The initial sulfate-to-iron molar ratio had a large effect on the settling properties of neutralized floc in both the sodium (Figure 15) and ammonium (Figure 16) systems. Settling curves were shifted to the right when sulfate was present, indicating slower overall settling. When comparing the settling time required to reach the discharge limit

(70 $\mathrm{mg} \mathrm{L}^{-1} ; \mathrm{C} / \mathrm{Co}=0.25$ ), the only significant model terms were sulfate to iron molar ratio and the cation*sulfate to iron molar ratio interaction (Table 12). The overall model was 
Table 8. Type III sums of squares and significance levels of main effects, interactions and orthogonal linear contrasts for Phase 1 duration time, final suspended solids concentration, and settling rate when comparing different initial suspended solids concentrations in the Na system.

\begin{tabular}{|c|c|c|c|c|c|c|}
\hline \multirow[b]{2}{*}{ Source } & \multicolumn{2}{|c|}{ Settling Time } & \multicolumn{2}{|c|}{ Suspended Solids Concentration } & \multicolumn{2}{|c|}{ Settling Rate } \\
\hline & $\mathrm{SS}^{\mathrm{a}} \times 10^{-5}$ & $\operatorname{Pr}>\mathrm{F}$ & $\mathrm{SS}^{\mathrm{a}} \times 10^{2}$ & $\operatorname{Pr}>\mathrm{F}$ & $\mathrm{SS}^{\mathrm{a}} \times 10^{7}$ & $\mathrm{Pr}>\mathrm{F}$ \\
\hline Solids & na & na & na & na & na & na \\
\hline Sulfate to Iron Molar Ratio & 3.36 & $<0.0001$ & 4.33 & $<0.0001$ & 17.68 & 0.0002 \\
\hline Solids*Sulfate to Iron Molar Ratio & na & na & na & na & na & na \\
\hline $\mathrm{pH}$ & 0.83 & 0.0008 & na & na & na & na \\
\hline Solids*pH & 0.61 & 0.0112 & na & na & na & na \\
\hline Sulfate to Iron Molar Ratio*pH & 1.09 & 0.0011 & 2.09 & 0.0396 & na & na \\
\hline Solids*Sulfate to Iron Molar Ratio*pH & 1.21 & 0.0026 & 3.40 & 0.0159 & na & na \\
\hline \multicolumn{7}{|l|}{ Contrasts } \\
\hline \multicolumn{7}{|l|}{ Sulfate to Iron Molar Ratio } \\
\hline Linear & 0.003 & 0.8105 & 1.30 & 0.0042 & 17.67 & $<0.0001$ \\
\hline Quadratic & 3.36 & $<0.0001$ & 3.04 & $<0.0001$ & 0.02 & 0.8748 \\
\hline \multicolumn{7}{|l|}{$\mathrm{pH}$} \\
\hline Linear & 0.05 & 0.3172 & na & na & na & na \\
\hline Quadratic & 0.78 & 0.0003 & na & na & na & na \\
\hline
\end{tabular}

a: Type III Sums of Squares for model main effects and interactions; Contrast Sums of Squares for linear contrasts 
Table 9. Solids, sulfate to iron molar ratio and $\mathrm{pH}$ effects on the average Phase 1 duration time, final suspended solids concentration, and settling rate when comparing different initial suspended solids concentrations in the Na system.

\begin{tabular}{lcccc}
\hline Parameter & Level & Settling Time $^{\mathrm{a}}$ & $\begin{array}{c}\text { Solids }^{2} \\
\text { Concentration }^{\mathrm{b}}\end{array}$ & Settling Rate $^{\mathrm{c}}$ \\
\hline \multirow{3}{*}{ Solids } & 275 & $\mathrm{~s}$ & $\mathrm{mg} \mathrm{L}^{-1}$ & $\mathrm{~s}^{-1}$ \\
& 400 & na & na & na \\
& & & na & na \\
Sulfate to Iron Molar Ratio & $0: 1$ & 71 & $9.6 \times 10^{-1}$ & $-5.2 \times 10^{-4}$ \\
& $2.5: 1$ & 236 & $9.3 \times 10^{-1}$ & $-2.8 \times 10^{-4}$ \\
& $5: 1$ & 66 & 1.0 & $-2.3 \times 10^{-5}$ \\
pH & 7 & 109 & na & na \\
& 8 & 178 & na & na \\
& 9 & 86 & na & na \\
\hline
\end{tabular}

a: Mean square error $=4.76 \times 103, \mathrm{df}=36$.

b: Mean square error $=1.39 \times 10^{-3}, \mathrm{df}=36$.

c: Mean square error $=8.01 \times 10^{-8}, \mathrm{df}=35$.

significant $(\operatorname{Pr}>\mathrm{F}=<0.0001)$ but the $\mathrm{R}^{2}$ was low (0.48), principally because the required time occurred in a relatively flat portion of the settling curve. There was a linear trend to increase the required time with increasing sulfate to iron molar ratio (Table 12), an effect that was more apparent in the ammonium system than in the sodium system (Figures 15 and 16). In the ammonium system, the discharge limit was never obtained when the sulfate to iron molar ratio was 5:1 (Figure 16). Averaged across both cations, it took 29 minutes to reach the discharge limit when sulfate was absent and at least 46 minutes when sulfate was present (Table 13). Settling time generally increased with the presence of sulfate in both cation systems (Figure 17). Without sulfate, flocs in the sodium system settled faster (Figure 17). With sulfate, flocs in the ammonium system settled faster (Figure 17).

Significant model effects for settling rates $(\mathrm{t}<300 \mathrm{~s})$ were cation, sulfate to iron molar ratio, $\mathrm{pH}$ and cation*pH (Table 12). Settling rates were faster in the sodium system than in the ammonium system (Table 13). The fastest settling rate occurred at $\mathrm{pH} 9$ and the slowest at $\mathrm{pH}$ 8. Although there was a significant effect of cation*pH on settling rates, this was not a cross-over type interaction and rates in the sodium system were never slower than significant effects, sulfate to iron molar in the ammonium system. The 


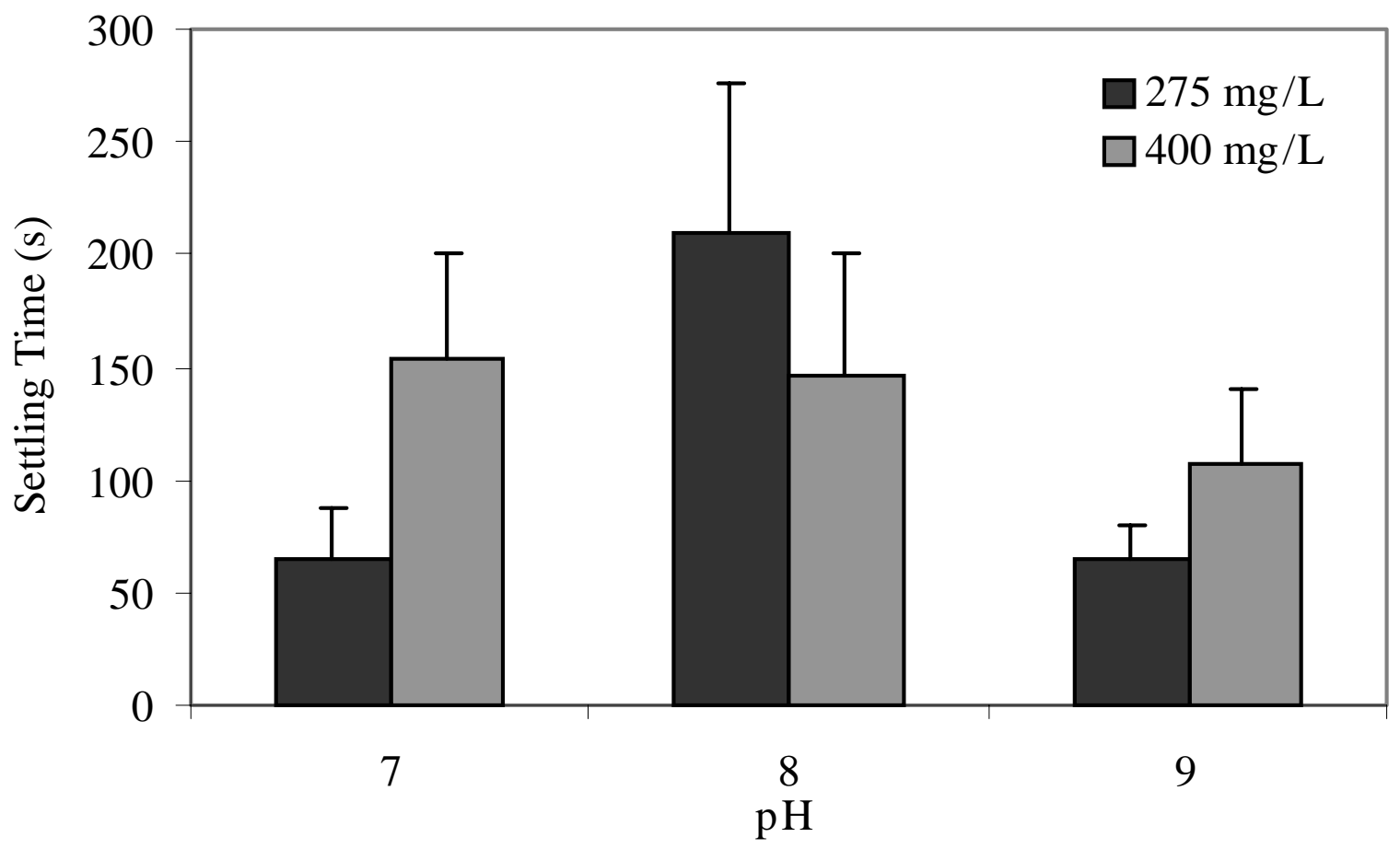

Figure 11. Average settling time (s) for Phase 1 as affected by $\mathrm{pH}$ and initial suspended solids concentration. Error bars represent standard deviation calculated for each subset of treatment interactions presented. $\mathrm{df}=8$ 
Table 10. . Type III sums of squares and significance levels of main effects, interactions and orthogonal linear contrasts for Phase 2 duration time, final suspended solids concentration, and settling rate when comparing different initial suspended solids concentrations in the Na system.

\begin{tabular}{|c|c|c|c|c|c|c|}
\hline \multirow[b]{2}{*}{ Source } & \multicolumn{2}{|c|}{ Settling Time } & \multicolumn{2}{|c|}{ Suspended Solids Concentration } & \multicolumn{2}{|c|}{ Settling Rate } \\
\hline & $\mathrm{SS}^{\mathrm{a}} \times 10^{-5}$ & $\operatorname{Pr}>\mathrm{F}$ & $\mathrm{SS}^{\mathrm{a}} \times 10^{1}$ & $\operatorname{Pr}>\mathrm{F}$ & $\mathrm{SS}^{\mathrm{a}} \times 10^{5}$ & $\operatorname{Pr}>\mathrm{F}$ \\
\hline Solids & na & na & 1.25 & 0.0008 & 0.43 & 0.0026 \\
\hline Sulfate to Iron Molar Ratio & 2.79 & $<0.0001$ & 8.44 & $<0.0001$ & 1.85 & $<0.0001$ \\
\hline Solids*Sulfate to Iron Molar Ratio & 0.73 & 0.0492 & 0.75 & 0.0269 & 0.39 & 0.0151 \\
\hline PH & na & na & na & na & na & na \\
\hline Solids*pH & na & na & na & na & na & na \\
\hline Sulfate to Iron Molar Ratio*pH & 4.30 & $<0.0001$ & na & na & 0.57 & 0.0170 \\
\hline Solids*Sulfate to Iron Molar Ratio*pH & na & na & na & na & na & na \\
\hline \multicolumn{7}{|l|}{ Contrasts } \\
\hline \multicolumn{7}{|l|}{ Sulfate to Iron Molar Ratio } \\
\hline Linear & 2.74 & $<0.0001$ & 7.22 & $<0.0001$ & 1.64 & $<0.0001$ \\
\hline Quadratic & 0.05 & 0.5032 & 1.22 & 0.0010 & 0.21 & 0.0308 \\
\hline \multicolumn{7}{|l|}{$\mathrm{pH}$} \\
\hline Linear & na & na & na & na & na & na \\
\hline Quadratic & na & na & na & na & na & na \\
\hline
\end{tabular}

a: Type III Sums of Squares for model main effects and interactions; Contrast Sums of Squares for linear contrasts 


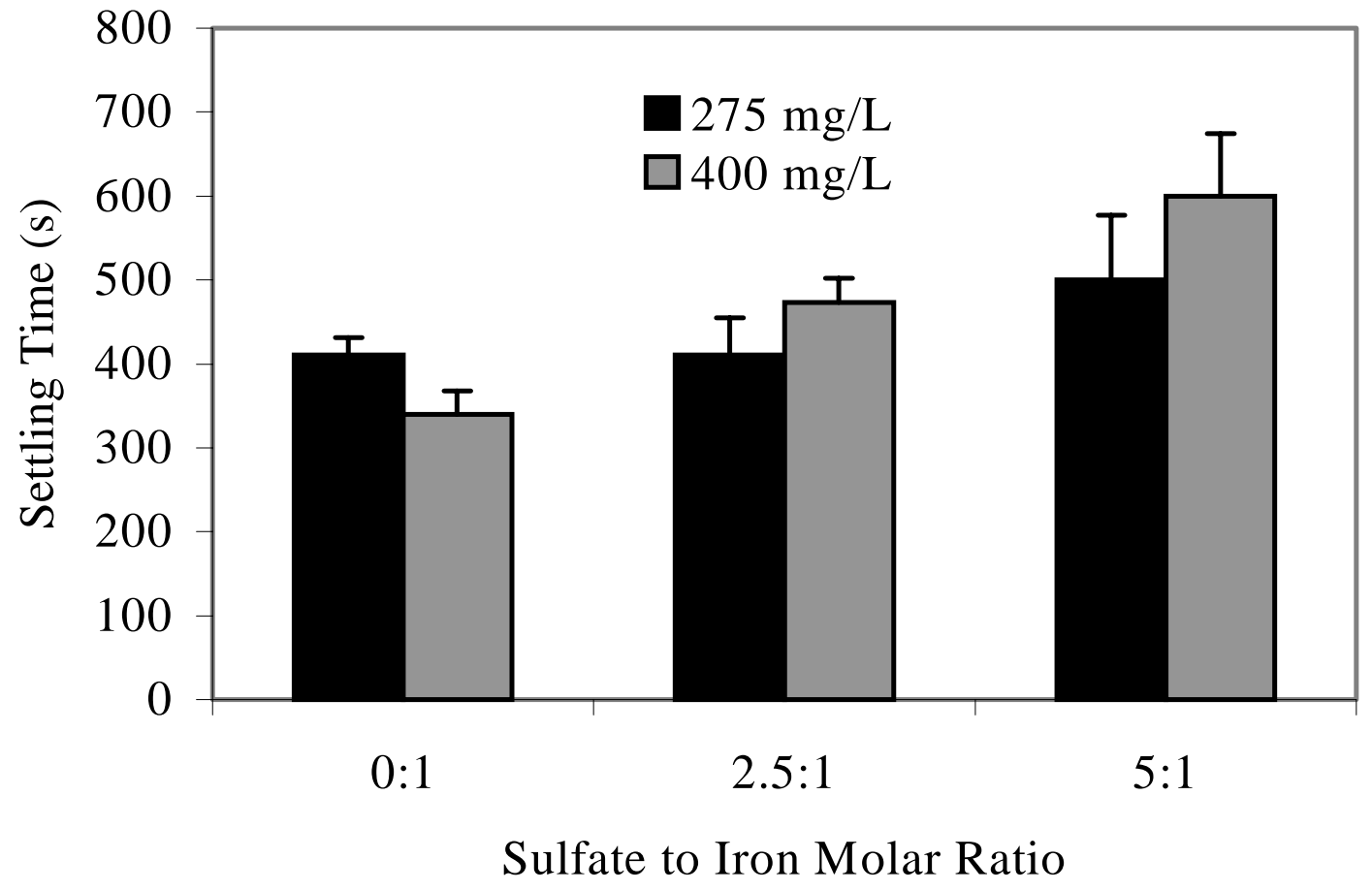

Figure 12. Average settling time in Phase 2 as affected by initial experiment suspended solids concentration and sulfate to iron molar ratio. Error bars represent standard deviation calculated for each subset of treatment interactions presented. $\mathrm{df}=8$ 
Table 11. Solids, sulfate to iron molar ratio and $\mathrm{pH}$ effects on the average Phase 2 duration time, final suspended solids concentration, and settling rate when comparing different initial solids concentrations in the Na system.

\begin{tabular}{|c|c|c|c|c|}
\hline Parameter & Level & Settling Time $^{\mathrm{a}}$ & $\begin{array}{c}\text { Solids } \\
\text { Concentration }^{\mathrm{b}}\end{array}$ & Settling Rate ${ }^{\mathrm{c}}$ \\
\hline \multirow{3}{*}{ Solids } & & $\mathrm{s}$ & $\mathrm{mg} \mathrm{L}^{-1}$ & $\mathrm{~s}^{-1}$ \\
\hline & 275 & na & $5.8 \times 10^{-1}$ & $-1.3 \times 10^{-3}$ \\
\hline & 400 & na & $4.8 \times 10^{-1}$ & $-1.9 \times 10^{-3}$ \\
\hline \multirow[t]{3}{*}{ Sulfate to Iron Molar Ratio } & $0: 1$ & 376 & $3.6 \times 10^{-1}$ & $-2.2 \times 10^{-3}$ \\
\hline & $2.5: 1$ & 442 & $6.0 \times 10^{-1}$ & $-1.9 \times 10^{-3}$ \\
\hline & $5: 1$ & 550 & $6.4 \times 10^{-1}$ & $-8.1 \times 10^{-4}$ \\
\hline \multirow[t]{3}{*}{$\mathrm{pH}$} & 7 & na & na & na \\
\hline & 8 & na & na & na \\
\hline & 9 & na & na & na \\
\hline
\end{tabular}

a: Mean square error $=1.11 \times 10^{4}, \mathrm{df}=36$.

b: Mean square error $=9.41 \times 10^{-3}, \mathrm{df}=36$.

c: Mean square error $=4.1 \times 10^{-7}, \mathrm{df}=40$

settling rates were slower near the PZNC, and increased linearly as the absolute difference between neutralization $\mathrm{pH}$ and PZNC increased (Table 13). Settling rates were significantly slower when sulfate was present (Table 13). Of the ratio and $\mathrm{pH}$ were the most important as determined by Type III sums of squares (Table 12).

\section{Imhoff Cone Settling $(t=1 \mathrm{hr})$}

\section{$\underline{\text { Settled Floc Mass }}$}

The analysis of variance model for the Imhoff cone data was significant for settled floc mass $(\operatorname{Pr}>\mathrm{F}=<0.0005)$. Significant model terms for settled mass were sulfate to iron molar ratio, $\mathrm{pH}$ and the sulfate to iron molar ratio* $\mathrm{pH}$ interaction (Table 14). Settled floc mass was greater when sulfate was present and greater at sulfate to iron molar ratio 5:1 than at 2.5:1 (Table 14), principally because of the large effect at sulfate to iron molar ratio 5:1 (Table 13). The significant linear trend to decrease settled mass with increasing $\mathrm{pH}$ was complicated by the sulfate to iron molar ratio*pH interaction (Table 14) and the large effect of sulfate to iron molar ratio at $\mathrm{pH} 7$ (Figure 18). The presence of sulfate at $\mathrm{pH} 7$ increased settled mass over that of $\mathrm{pH} 8$ or 9 (Figure 18). Compared to the zero 


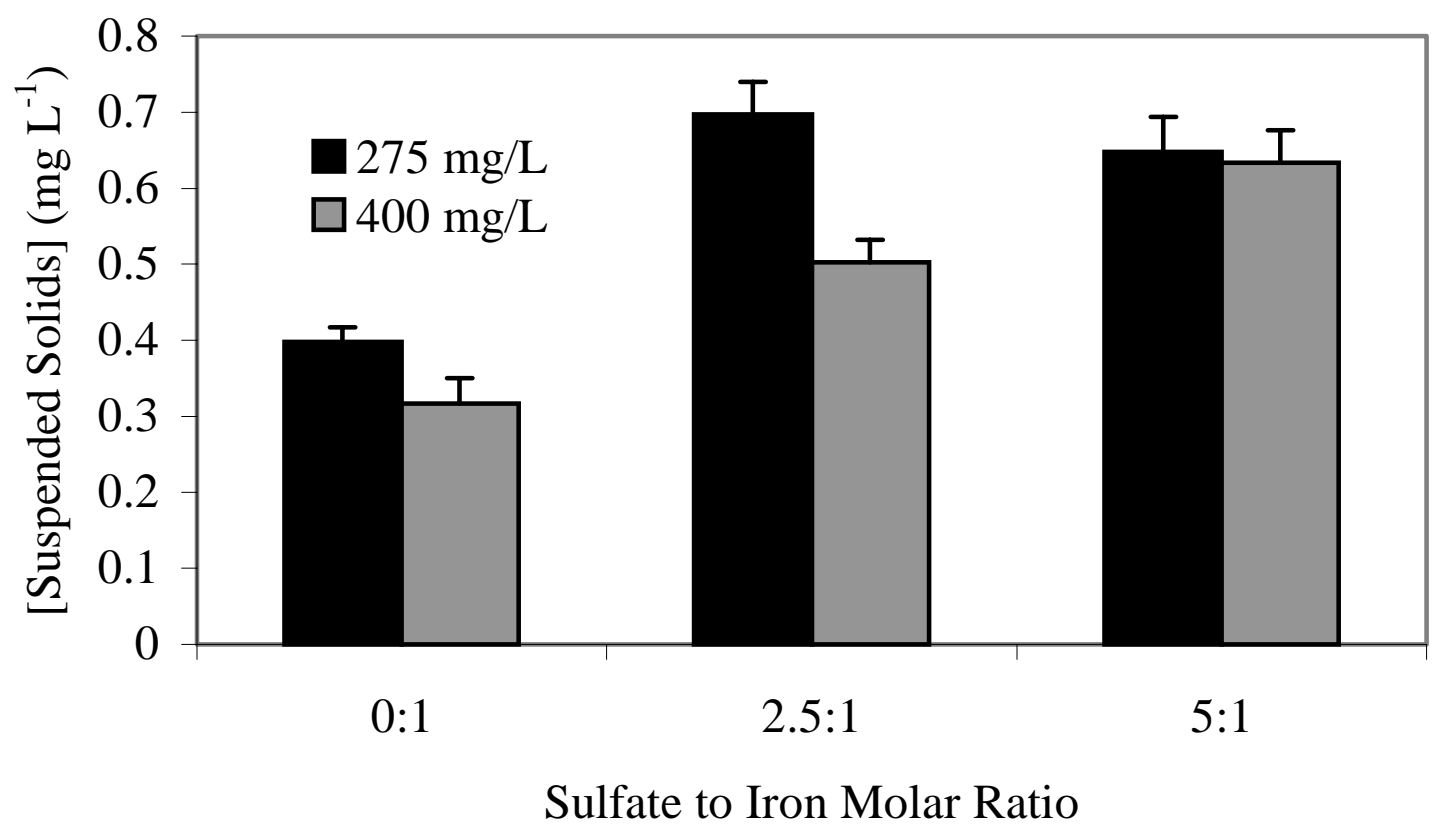

Figure 13. Average final Phase 2 suspended solids concentration as affected by initial experiment suspended solids concentration and sulfate to iron molar ratio. Error bars represent standard deviation calculated for each subset of treatment interactions presented. $\mathrm{df}=8$ 


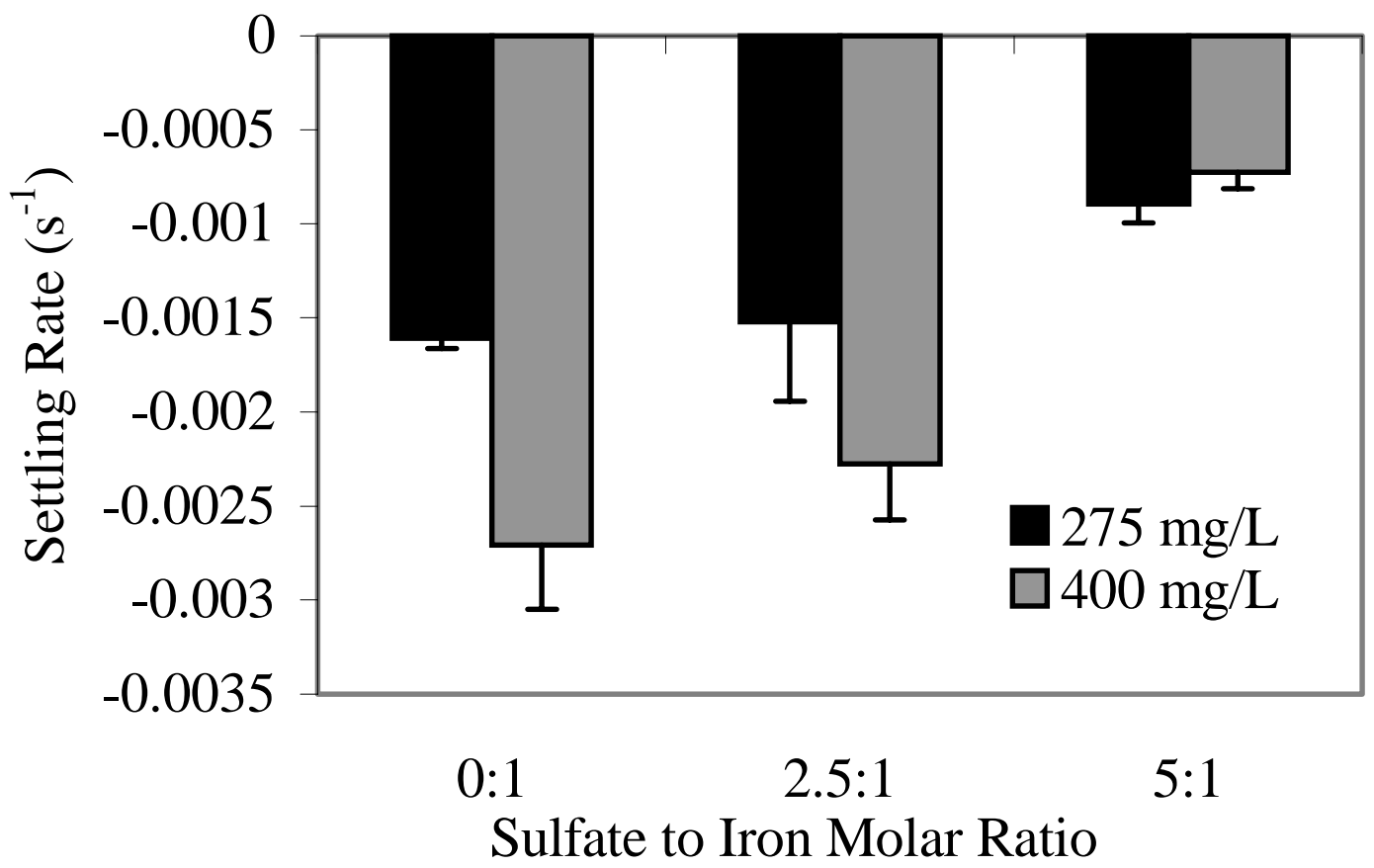

Figure 14. Average settling rate in Phase 2 as affected by initial experiment suspended solids concentration and sulfate to iron molar ratio. Error bars represent standard deviation calculated for each subset of treatment interactions presented. $\mathrm{df}=8$ 


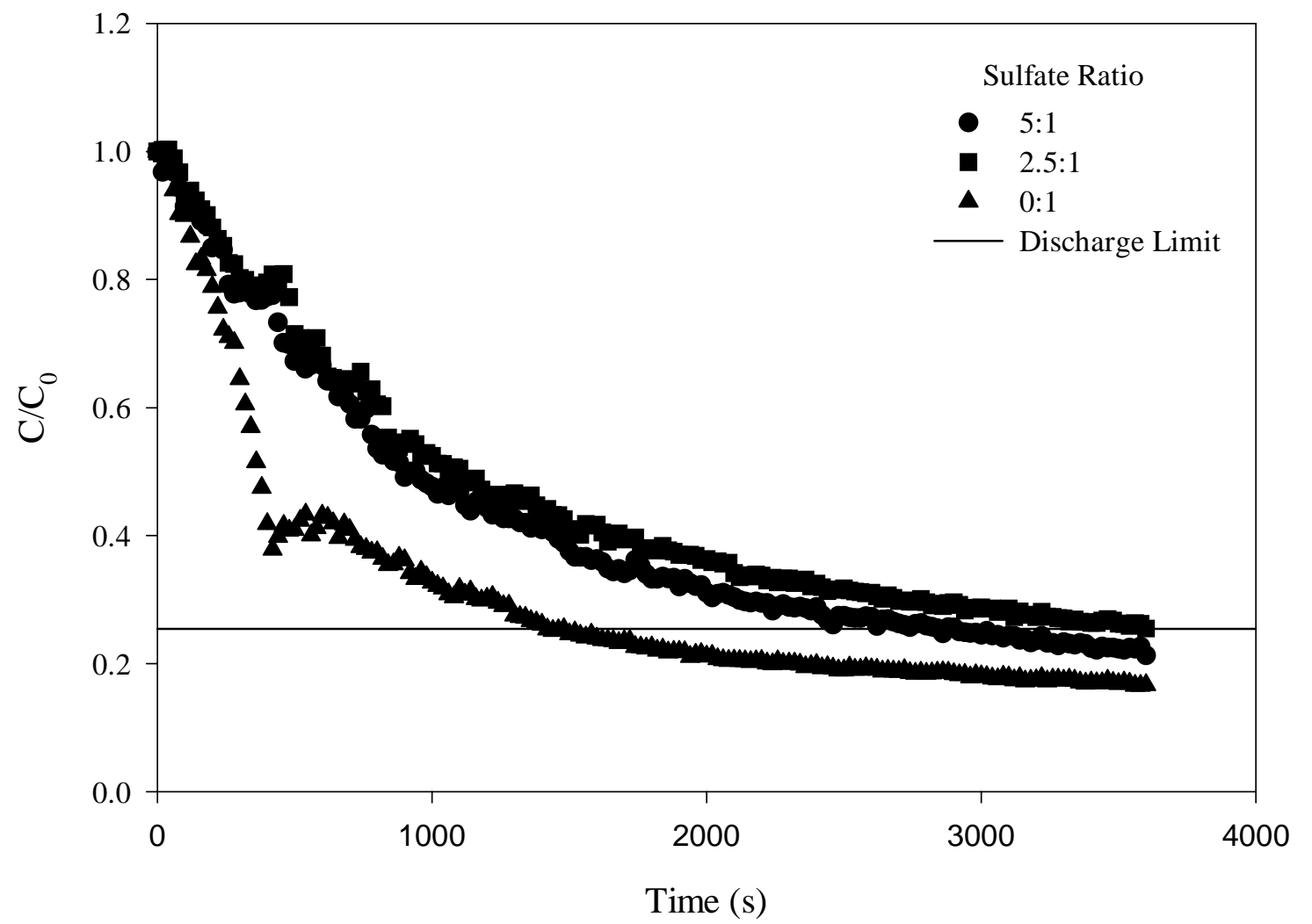

Figure 15. Settling curves for each sulfate to iron molar ratio in the sodium system. Discharge limit (70 $\left.\mathrm{mg} \mathrm{L}^{-1} \mathrm{TSS}\right)$ indicated by the solid line. 


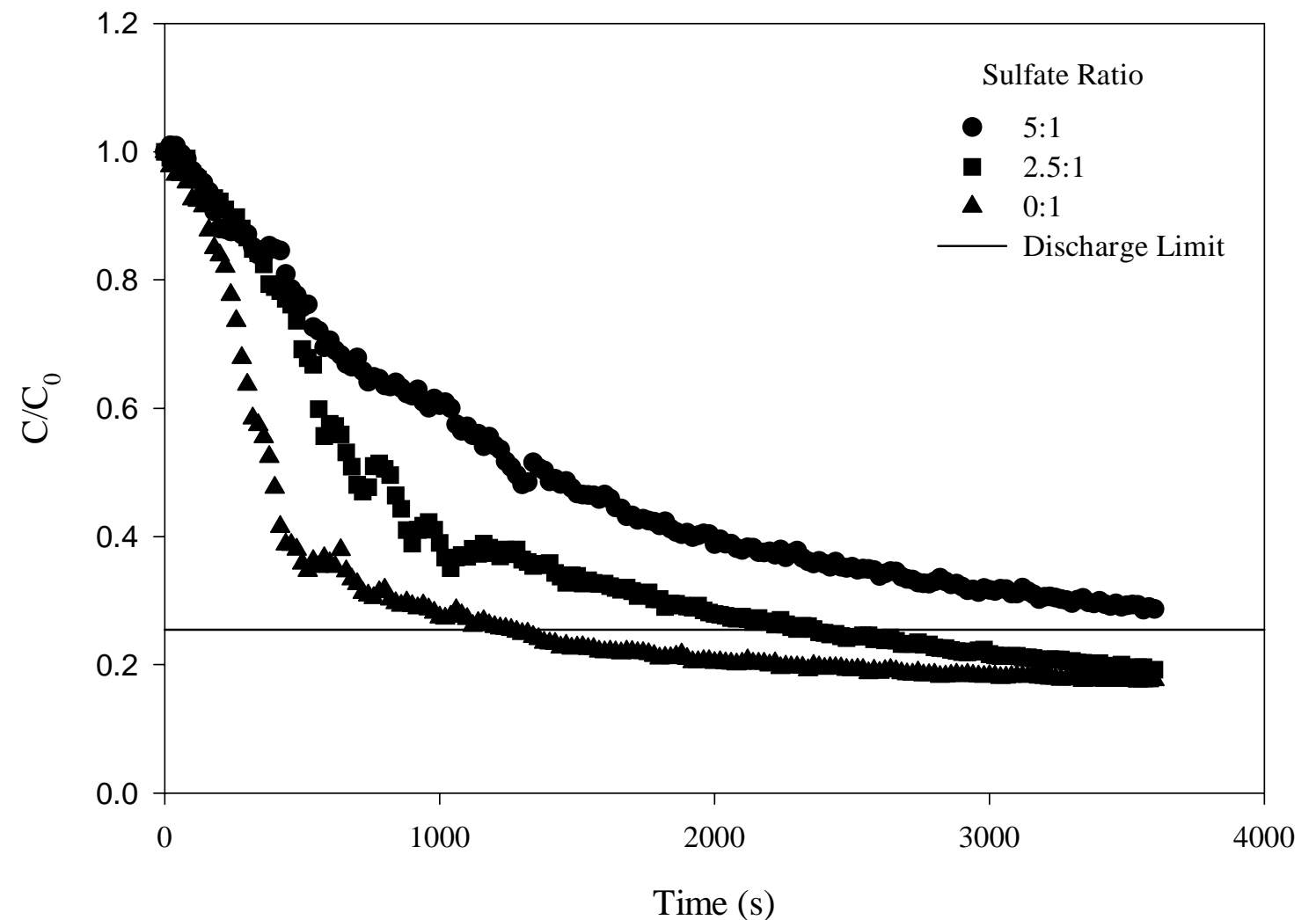

Figure 16. Settling curves for each sulfate to iron molar ratio in the ammonium system. Discharge limit (70 $\left.\mathrm{mg} \mathrm{L}^{-1} \mathrm{TSS}\right)$ indicated by the solid line. 
Table 12. Type III sums of squares and significance levels of main effects, interactions and orthogonal linear contrasts for settling time required to reach the NPDES discharge limit of $70 \mathrm{mg} \mathrm{L}^{-1}$ and initial settling rate $(\mathrm{t}<300 \mathrm{~s})$.

\begin{tabular}{|c|c|c|c|c|}
\hline \multirow[b]{2}{*}{ Source } & \multicolumn{2}{|c|}{ Settling Time } & \multicolumn{2}{|c|}{ Initial Settling Rate } \\
\hline & $\mathrm{SS}^{\mathrm{a}} \times 10^{-7}$ & $\operatorname{Pr}>\mathrm{F}$ & $\mathrm{SS}^{\mathrm{a}} \times 10^{7}$ & $\operatorname{Pr}>\mathrm{F}$ \\
\hline Cation & na & na & 3.94 & 0.0236 \\
\hline Sulfate to Iron Molar Ratio & 1.76 & $<0.0001$ & 27.48 & $<0.0001$ \\
\hline Cation*Sulfate to Iron Molar Ratio & 0.50 & 0.0261 & na & na \\
\hline $\mathrm{pH}$ & na & na & 11.84 & 0.0010 \\
\hline Cation*pH & na & na & 5.13 & 0.0363 \\
\hline Sulfate to Iron Molar Ratio*pH & na & na & na & na \\
\hline Cation*Sulfate to Iron Molar Ratio*pH & na & na & na & na \\
\hline \multicolumn{5}{|l|}{ Contrasts } \\
\hline \multicolumn{5}{|l|}{ Sulfate to Iron Molar Ratio } \\
\hline Linear & 1.59 & $<0.0001$ & 23.99 & $<0.0001$ \\
\hline Quadratic & 0.17 & 0.0733 & 3.49 & 0.0324 \\
\hline \multicolumn{5}{|l|}{$\mathrm{pH}$} \\
\hline Linear & na & na & 2.96 & 0.0476 \\
\hline Quadratic & na & na & 8.87 & 0.0011 \\
\hline
\end{tabular}

sulfate treatment, there was no effect of sulfate to iron molar ratio on settled mass at $\mathrm{pH} 8$ or 9 (Figure 18).

\section{Settled Floc Volume}

The analysis of variance model for the Imhoff cone data were also significant for settled floc volume $(\operatorname{Pr}>\mathrm{F}=<0.0001)$. Significant model terms for settled floc volumes were cation, sulfate to iron molar ratio and $\mathrm{pH}$ (Table 14). Settled floc volumes were larger in the sodium system than in the ammonium system (Table 13). There was a significant linear trend to decrease settled volume as $\mathrm{pH}$ increased and so the minimum settled volume did not occur near the PZNC (Table 13). The effect of neutralization end $\mathrm{pH}$ on EC and ionic strength was small (data not shown). Floc volume was smaller when sulfate was present, with the largest floc volume occurring at sulfate to iron molar ratio 0:1 (Table 13). Settling rates were faster in suspensions without sulfate (Table 13). Although the main effects of cation and $\mathrm{pH}$ were significant, sulfate to iron molar ratio 
Table 13. Cation, sulfate to iron molar ratio and $\mathrm{pH}$ effects on the average settled floc mass and volume, initial settling rates and time.

\begin{tabular}{lccccc}
\hline Parameter & Level & $\begin{array}{c}\text { Settling } \\
\text { Time }^{\mathrm{a}}\end{array}$ & $\begin{array}{c}\text { Initial Settling } \\
\text { Rate }^{\mathrm{b}}\end{array}$ & $\begin{array}{c}\text { Settled } \\
\text { Mass }^{\mathrm{c}}\end{array}$ & $\begin{array}{c}\text { Settled } \\
\text { Volume }^{\mathrm{d}}\end{array}$ \\
\hline \multirow{3}{*}{ Cation } & & $\mathrm{s}$ & $\mathrm{s}$ & $\mathrm{g}$ & $\mathrm{mL}$ \\
& $\mathrm{Na}$ & na & $-8.6 \times 10^{-4}$ & $8.90 \times 10^{-2}$ & 23.3 \\
& $\mathrm{NH}_{4}$ & na & $-6.8 \times 10^{-4}$ & $8.71 \times 10^{-2}$ & 22.0 \\
\multirow{3}{*}{ Sulfate to Iron Molar Ratio } & $0: 1$ & 1740 & $-10.8 \times 10^{-4}$ & $8.57 \times 10^{-2}$ & 25.2 \\
& $2.5: 1$ & 2779 & $-5.7 \times 10^{-4}$ & $8.66 \times 10^{-2}$ & 20.0 \\
& $5: 1$ & 3070 & $-6.6 \times 10^{-4}$ & $9.18 \times 10^{-2}$ & 22.8 \\
& & & & & \\
$\mathrm{pH}$ & 7 & na & $-7.7 \times 10^{-4}$ & $9.05 \times 10^{-2}$ & 23.8 \\
& 8 & na & $-5.9 \times 10^{-4}$ & $8.69 \times 10^{-2}$ & 22.7 \\
& 9 & na & $-9.5 \times 10^{-4}$ & $8.69 \times 10^{-2}$ & 21.6 \\
\hline
\end{tabular}

a: Mean square error $=5.00 \times 10^{5}, \mathrm{df}=48$.

b: Mean square error $=7.04 \times 10^{-8}, \mathrm{df}=36$.

c: Mean square error $=1.86 \times 10^{-5}, \mathrm{df}=35$.

$\mathrm{d}$ : Mean square error $=4.20, \mathrm{df}=36$.

was the single most important parameter (Table 14) as determined by Type III model sums of squares. Although statistically significant, differences in settled floc volumes were small $(<7 \%)$ and so may not be of practical significance. 


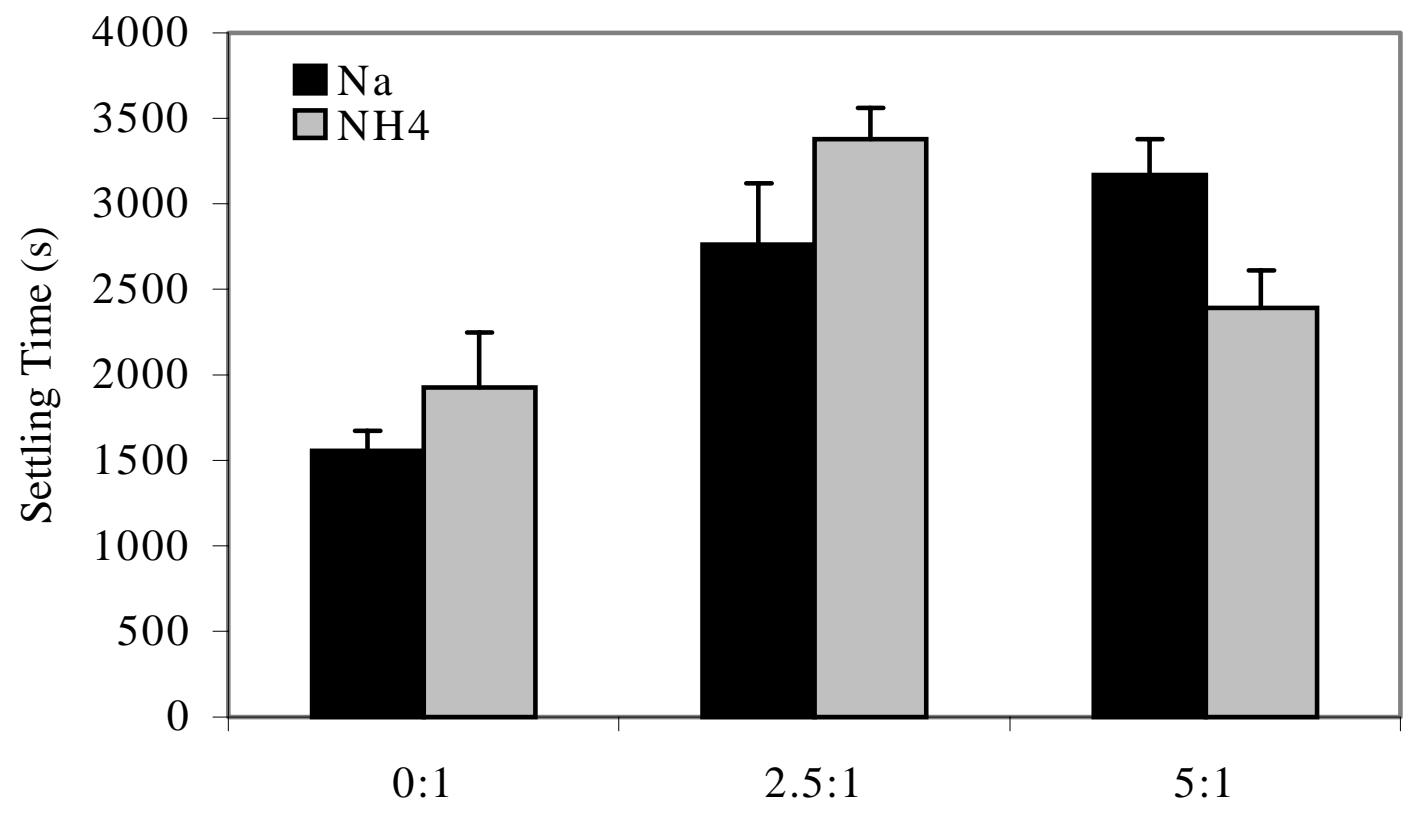

Sulfate to Iron Molar Ratio

Figure 17. Average settling time to reach discharge limits as affected by cation and sulfate to iron molar ratio. Error bars represent standard deviation calculated for each subset of treatment interactions presented. $\mathrm{df}=8$ 
Table 14. Type III sums of squares and significance levels of main effects, interactions and orthogonal linear contrasts for average settled floc mass and volume after one hour in Imhoff $^{\circledR}$ cones.

\begin{tabular}{|c|c|c|c|c|}
\hline \multirow[b]{2}{*}{ Source } & \multicolumn{2}{|c|}{ Mass } & \multicolumn{2}{|c|}{ Volume } \\
\hline & $\mathrm{SS}^{\mathrm{a}} \times 10^{4}$ & $\operatorname{Pr}>F$ & $\mathrm{SS}^{\mathrm{a}}$ & $\operatorname{Pr}>\mathrm{F}$ \\
\hline Cation & na & na & 22.82 & 0.0254 \\
\hline Sulfate to Iron Molar Ratio & 3.672 & 0.0004 & 240.73 & $<0.0001$ \\
\hline Cation*Sulfate to Iron Molar Ratio & na & na & na & na \\
\hline $\mathrm{pH}$ & 1.592 & 0.0216 & 41.82 & 0.0123 \\
\hline Cation*pH & na & na & na & na \\
\hline Sulfate to Iron Molar Ratio*pH & 3.832 & 0.0022 & na & na \\
\hline Cation*Sulfate to Iron Molar Ratio*pH & na & na & na & na \\
\hline \multicolumn{5}{|l|}{ Contrasts } \\
\hline \multicolumn{5}{|l|}{ Sulfate to Iron Molar Ratio } \\
\hline Linear & 3.300 & 0.0002 & 51.12 & 0.0013 \\
\hline Quadratic & 0.372 & 0.1659 & 189.61 & $<0.0001$ \\
\hline \multicolumn{5}{|l|}{$\mathrm{pH}$} \\
\hline Linear & 1.195 & 0.0158 & 41.82 & 0.0032 \\
\hline Quadratic & 0.429 & 0.1374 & 0 & 1.00 \\
\hline
\end{tabular}

a: Type III Sums of Squares for model main effects and interactions; Contrast Sums of Squares for linear contrasts 


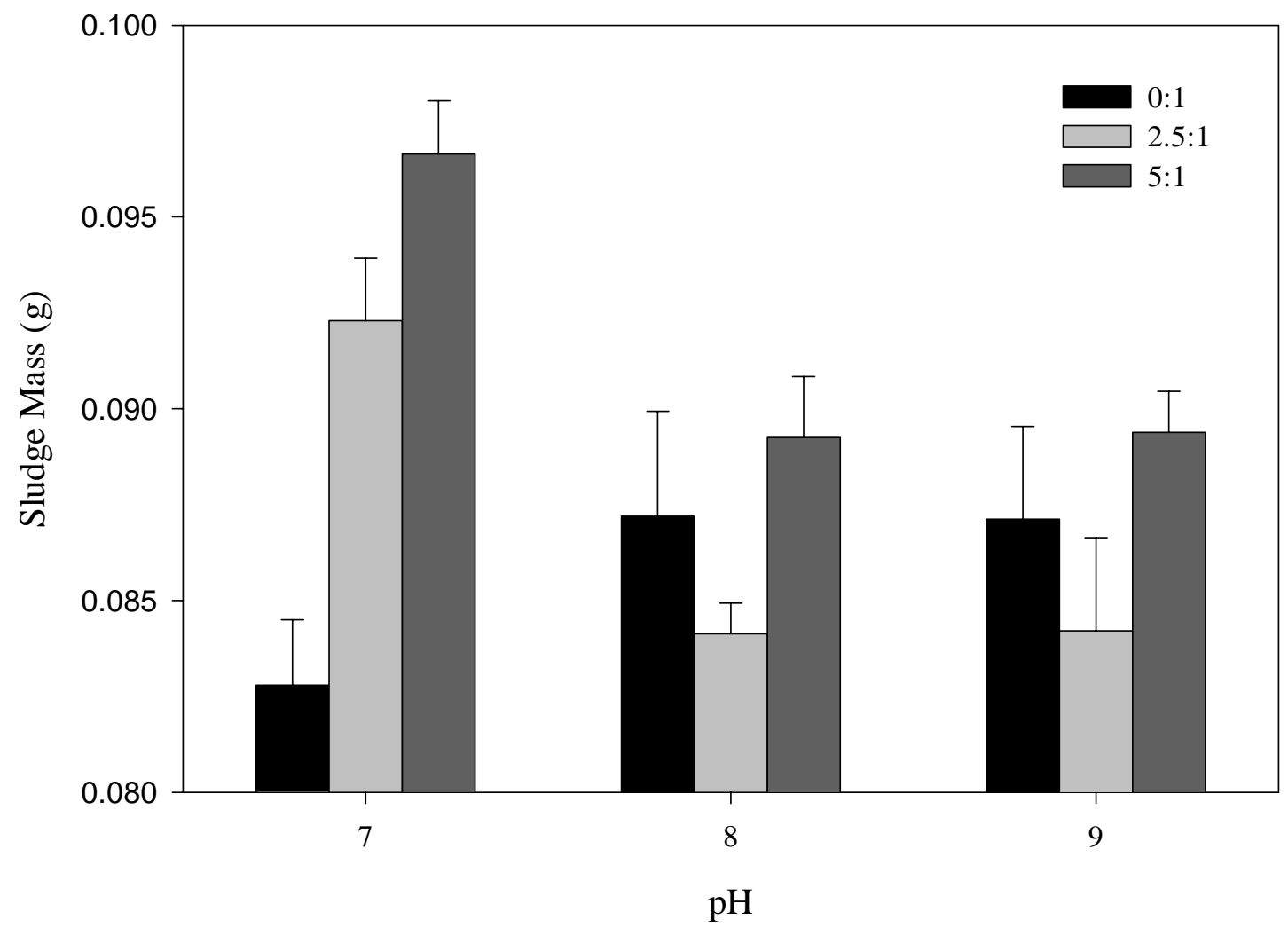

Figure 18. Average settled sludge mass (g) for the Imhoff Settling Cones as affected by $\mathrm{pH}$ and sulfate to iron molar ratio. 


\section{Discussion}

\section{PZNC}

A PZNC of 7.7 is lower than that reported by Parks (1965) for amorphous iron oxide (8.5), but is comparable to other reported values when $\mathrm{CO}_{2}$ is not excluded from the system (e.g. Herrera-Ramos and McBride, 1996). The small shift calculated in this experiment may be due to the preferential adsorption of chloride (introduced as $\mathrm{FeCl}_{3} \cdot 6 \mathrm{H}_{2} \mathrm{O}$ ) over sulfate (Kanungo, 1994). Evaluation of PZNC in this range with an expanded subset of $\mathrm{pH}$ values may reveal more specific information.

\section{Effect of Cation on Settling Properties}

Phase 1 times were longer in the ammonium system than in the sodium system, indicating larger aggregate size. The smaller hydrated radius of ammonium may permit the agglomeration of more primary particles within an aggregate. The higher suspended solids concentrations found in the sodium system in phase 1 may be related to the level of flocculation. Since we found that sodium system precipitates spent less time in phase 1 than ammonium precipitates, it is reasonable to suggest that sodium precipitates may contain more small aggregates and primary particles than those in the ammonium system. This higher number of particle types as compared to fewer, large aggregates in the ammonium system may give the appearance of a higher suspended solids concentration.

At the highest sulfate to iron molar ratio and in the ammonium system in phase 2 , settling time is lengthened; not a surprising result. The slight decrease with 2.5:1 sulfate to iron molar ratio indicates that ammonium may initially help counteract the inhibitory effects of sulfate on particle formation and growth (Diz et al., 1999). The same effect is observable in the sodium system to a lesser extent (Figure 6). The mean settling rate in phase 2 was faster in the ammonium system than in the sodium (Table 5), indicating larger aggregates. This data correlates with the observed settling rates of the ammonium system in phase 1 . Together they suggest a greater effective radius of the reflocculated particles (vs. sodium) which, according to Stoke's Law, would settle faster. 


\section{Effect of Sulfate to Iron Molar Ratio on Settling Properties}

The quadratic trend with respect to sulfate to iron molar ratio in phase 1 tends to support the possibility of particle growth inhibition consistent with the observations of Diz et al. (1999). The smaller time in the system without sulfate (versus those with sulfate) directly supports this idea. It is possible that this effect was slightly mitigated in the $5: 1$ sulfate to iron molar ratio by the interaction of cation and $\mathrm{pH}$ with sulfate to iron molar ratio, since the sums of squares for this interaction was half as strong as any of the effects individually (Tables 2 and 3). If such were the case, it suggests that diffuse double layer properties were more significant at this ratio than attachment site blocking by sulfate. A closer look at the $\mathrm{pH}^{*}$ sulfate to iron molar ratio interaction shows that sulfate may be more effective at slowing growth processes at or near the PZNC (Figure 4). Given the significant interaction of moderate sulfate to iron molar ratio and $\mathrm{pH} 8$ in phase 1 with regard to final suspended solids concentration (Figure 5), it may be supposed that this level of sulfate may shift the PZNC enough to cause more settling to occur; or the $\mathrm{pH}$ mitigates the inhibitory effect of sulfate on particle growth (Diz et al., 1999). Decreased settling rates with increasing sulfate to iron molar ratios in phase 1 also suggest an inhibition of HFO growth rates consistent with Diz et al. (1999).

The effect of sulfate to iron molar ratio on growth rate is more apparent near the PZNC in phase 2, resulting in longer settling times, suggesting smaller particles. The increased final suspended solids concentration in both cation systems lends support to the idea that sulfate may cause the formation of smaller particles that do not settle as well.

While compression generally occurs in any settling regime, the significant effect in phase 4 of this study proved to be sulfate to iron molar ratio. The quadratic trend exhibiting a maximum near sulfate to iron molar ratio 5:1 (Tables 6 and 7), indicates that more compression occurs in the presence of sulfate. This data may further support the idea of the bridging mechanisms suggested by Rajan (1978) and Parfitt and Smart (1978).

\section{Effect of pH on Settling Properties}

Phase 1 systems exhibited significant quadratic trends with respect to $\mathrm{pH}$ with maximum settling time and minimum final suspended solids concentration both occurring at $\mathrm{pH} 8$ (Tables 2 and 3). The increase in settled solids is consistent with a PZNC near $\mathrm{pH}$ 
8 , permitting maximum settling due to minimized repulsive forces. The treatment $\mathrm{pH}$ was also an important factor for phase 2 settling time, again exhibiting a maximum at $\mathrm{pH} 8$ (Tables 4 and 5). It is interesting to note the increased time characteristic of these systems. The result would seem to indicate that field treatment systems that would neutralize AMD to the PZNC must account for an increase in required residence time to allow for the induction of settling.

\section{Effect of Solids Concentration on Settling Properties}

The higher repulsive forces among particles farther from the PZNC in phase 1 appear to result in faster initiation of settling when initial solids concentration is lower. In the higher initial suspended solids concentration, phase 1 settling time is much less $\mathrm{pH}$ dependent (Figure 11). Mean final solids concentrations were higher in phase 2 in the 275 mg SS L ${ }^{-1}$ initial suspended solids system (Table 11) as would be expected with a lower collision frequency system. A significant quadratic trend was observed with regard to sulfate to iron molar ratio (maximum near 5:1) (Tables 10 and 11), the effect of sulfate being initially less apparent at the lower suspended solids concentration (Figure 12). Sulfate had greater effect at higher suspended solids concentration than at lower suspended solids concentration across sulfate to iron molar ratios. Systems with sulfate and high suspended solids concentration became slower than the lower suspended solids concentration systems indicating that sulfate to iron molar ratio was more important than suspended solids concentration at the levels studied (Figure 12). Phase 2 mean settling rates were faster in the $400 \mathrm{mg} \mathrm{SS} \mathrm{L}^{-1}$ system (Table 11) indicating an increased frequency of collision. The increase in settling rate with increasing suspended solids concentration, as observed in the comparison of sodium flocs (Table 11) is consistent with previous findings (Glasgow, 1989). It is likely that the overall decrease in rate expected with increasing sulfate to iron molar ratio was limited somewhat by the solids effect at low suspended solids concentration (Figure 14).

\section{Ability to Meet Discharge Criteria (70 $\left.\mathrm{mg} \mathrm{L}^{-1} \mathrm{TSS}\right)$}

The faster settling times of ammonium flocs in the presence of sulfate (resulting in an inability to meet discharge limits) indicates larger particles containing more 
interstitial water resulting in less compact final volumes (Glasgow, 1989). Since sodium has a larger hydrated radius than ammonium, greater aggregation would be expected in the ammonium system at or near the PZNC. This same expectation holds true for sulfate systems (versus systems without sulfate) because sulfate can act as a bridging ligand. That settling rates were slower with these conditions may indicate that secondary aggregates were less dense than primary particles. Increased interstitial water in secondary aggregates has been implicated in the negative log-linear relationship between floc diameter and floc density in clay systems (Tambo and Watanabe 1979). In neutralized iron oxide suspensions, the effects of $\mathrm{pH}$ and anions on particle morphology (Baltpurvins et al., 1996; Parida and Das, 1996) may also play a role. Slower initial settling rates near the calculated PZNC may indicate more time spent in floc aggregation processes.

\section{Imhoff Cone Settling}

$\underline{\text { Settled Floc Mass }}$

The lack of cation effect on settled mass indicates the mass of incorporated $\mathrm{Na}$ or $\mathrm{NH}_{4}$ was either negligible or equivalent between treatments (Table 14). This result is not surprising because at $\mathrm{pH} 7$ to 9 the net negative surface charge would be negligible, and a jarosite phase would not be stable (Bigham et al., 1996b). The sulfate to iron molar ratio effect on mass (Table 14 and Figure 18) could implicate a decrease in solubility of HFO due to sulfate in solution, incorporation of sulfate into the precipitate molecular structure, or adsorption to the precipitate surface, thereby increasing the mass. It is further possible that sulfate may be acting as a catalyst for settling, or that our results represent a new phase with an as yet unidentified solubility constant. Since an increase in sulfate should, in fact, allow more iron to be in solution in the form of iron sulfate complexes (Diz et al., 1999), the first option does not seem likely. Although the solubility diagrams previously presented in this paper do not readily show this relationship, we recognize that these calculations are simplistic. In reality, the complexation coefficients used to generate the curves may not be accurate, and the complexes actually forming are likely not fully represented. Given that schwertmannite, jarosite and other iron sulfate minerals are generally found at $\mathrm{pH}$ values below the range of consideration (Bigham et al., 1996a and 
1996b; Brady et al., 1986; Diz et al., 1999; Langmuir, 1997; Lindsay, 1979), sulfate incorporation also seems unlikely. However, Figure 18 shows an increase in settled floc mass of the no sulfate system with increasing $\mathrm{pH}$ and a decrease in mass with increasing $\mathrm{pH}$ for those systems containing sulfate. This trend would seem to indicate a shift in the mineral form being generated with increasing $\mathrm{pH}$, in agreement with previously referenced authors. The edge of the tension zone between iron sulfate and amorphous iron mineral formation may be represented by this data. It is also possible that the increase in mass with increasing sulfate to iron molar ratio is in part due to surface adsorption of sulfate. Higher masses are seen in the sulfate systems below the calculated PZNC than in those above it, as would be expected with a net positive surface charge below the calculated PZNC of 7.7. Desorption of sulfate with increasing $\mathrm{pH}$ would be consistent with Rose and Ghazi (1997). Increased particle size and complexity as reported by Brady et al. (1986) may also play a role. Further, this data may provide indirect evidence for a shift in the PZNC due to sulfate adsorption since the greater masses in the sulfate system are found at $\mathrm{pH} 7$.

\section{$\underline{\text { Settled Floc Volume }}$}

The larger settled floc volumes in the sodium (versus ammonium) system may be explained by the fact that the sodium ion has a larger hydrated radius than does ammonium. While the smallest settled volume, in theory, should be found near the PZNC, the data did not yield this pattern. It is likely that the presence of sulfate affected the location of the actual PZNC since the sums of squares show sulfate to iron molar ratio to be the most important factor for settled volumes. Since the effect of neutralization $\mathrm{pH}$ on EC and ionic strength was small, diffuse double layer compression is an unlikely explanation for this trend. It may also be that the range of $\mathrm{pH}$ investigated was too small to observe the expected minima in settled floc volume or that floc properties were changing during the course of the experiment. Rates of crystallization and surface charge reduction have been shown to increase as neutralization $\mathrm{pH}$ increases (Lahann, 1976). It is also interesting to note that the density of the settled floc in the sulfate solutions was on average 7 to $27 \%$ higher than the solutions without sulfate (Table 13). This difference may be indirect evidence for the formation of ring structures (Rajan, 1978), or binuclear 
bridging complexes (Parfitt and Smart, 1978). These six-membered structures between a sulfate ion and 2 adjacent iron atoms may give the HFO enough order to its structure to collapse the volumes to a better fit packing arrangement.

\section{Conclusions}

The pre-neutralization sulfate to iron molar ratio was the most important factor for determining settling properties of simulated AMD. Floc generated in the presence of sulfate had longer lag times, slower initial settling rates, took longer to reach desired discharge limits, and had smaller settled volumes and greater densities than those precipitated in the absence of sulfate. Although there was a significant effect of $\mathrm{pH}$ on many parameters measured, the effects were less important than sulfate to iron molar ratio. There was a small but significant effect of the neutralizing cation with the largest settled volumes, smallest suspended solids concentration after reflocculation, and fastest combined phase 1 and 2 settling rates observed in the sodium system. A greater effect was seen for phase 1 times; the time required to begin initial settling being twice as long in the ammonium system. Within the sodium system more specifically, initial solids concentration proved to have a significant effect on reflocculation times and final concentrations, reflocculation rates and initial settling properties, with the higher solids concentration generally increasing rates and reducing times.

The systems studied here were much simpler than actual acid mine drainage in that the possible effects of $\mathrm{Mn}^{2+}, \mathrm{Al}^{3+}, \mathrm{Fe}^{2+}$, and $\mathrm{Ca}^{2+}$ were not considered. Calcium can enter the system either in the initial solution, or as the cation accompanying the neutralization chemical $\left(\mathrm{CaO}, \mathrm{Ca}(\mathrm{OH})_{2}, \mathrm{CaCO}_{3}\right)$. The occlusion of gypsum $\left(\mathrm{CaSO}_{4}\right)$ crystals within secondary aggregates has been observed (Brown et al. 1994) and could have significant effects on the settling properties of AMD floc. The effects of initial $\mathrm{Fe}^{2+}$ concentrations need attention because the minerals formed when $\mathrm{Fe}^{2+}$ solutions are oxidized and neutralized are apparently different than those formed when $\mathrm{Fe}^{3+}$ solutions are neutralized, at least in acidic solutions (Bigham et al. 1996a). Interactions between $\mathrm{Fe}^{2+}$ and $\mathrm{Al}^{3+}$ have also been reported, with significant $\mathrm{Fe}^{2+}$ occlusion into neutralized $\mathrm{Al}$ polymers (Bertsch et al. 1989). The data of Dempsey and Jeon (2001) show an increase in the settling rate as sulfate to iron molar ratio increased when iron entered the system as 
$\mathrm{Fe}^{2+}$, a result exactly opposite of ours. Manganese introduces the complications previously discussed (Davies and Morgan, 1989). Additionally, the effect of the ratio of base added to iron in solution should be given greater attention as it relates to nucleation rate. The decrease in floc formation induction time noted by Diz et al. (1999) may have great importance to the prediction of lag phase behavior.

In the more in depth study of the sodium system, initial suspended solids concentration was never the most important factor. It was, though, a contributing one that should be considered. It may be possible to counter the inhibitory effects of sulfate on settling properties if a higher initial suspended solids concentration is achieved.

The results shown here indicate that prediction and control of floc settling rates may be possible with knowledge of several AMD characteristics, namely the sulfate to iron molar ratio and treatment chemical effect, with an understanding of the interaction of initial suspended solids concentration and $\mathrm{pH}$ with these factors. Adjustments will have to be made to control for suspended solids concentration after treatment as this concentration varies somewhat due to the solution characteristics. Settleability may be optimized for sulfate-free acid mine drainage by using the appropriate PZNC as a neutralization endpoint. For those drainages containing sulfate, it is apparent that sulfate to iron molar ratio exerts a greater influence on settleability than does $\mathrm{pH}$ and, therefore, must be the characteristic of consideration. Treatment chemical cation must also be considered as some cations seem to lead to larger aggregates with more interstitial water. These aggregates result in larger settled floc volumes, an undesirable effect in the field.

There is considerably more work that needs to be done before a complete model of the settling properties of actively treated acid mine drainage floc can be developed. Specific needs include a quantitative description of a) particle morphology as a function of neutralizing conditions, b) the effects of $\mathrm{Ca}^{2+}, \mathrm{Fe}^{2+}, \mathrm{Mn}^{2+}$ and $\mathrm{Al}^{3+}, \mathrm{c}$ ) the effects of other solid phases such as primary minerals (e.g. clays) and secondary precipitates (e.g. $\left.\mathrm{Ca}(\mathrm{OH})_{2}, \mathrm{CaCO}_{3}, \mathrm{CaSO}_{4}\right)$, and d) the effects of a greater range of sulfate to iron molar ratios in combination with varying initial suspended solids concentrations. 


\section{References}

Ackman, T. 1982. Sludge disposal from acid mine drainage treatment. U.S. Bureau of Mines, Report of Invest. 8672, Pittsburgh, PA.

Ashby, J.C. 1998. Utility byproducts used for acid-mine-drainage abatement at Mettiki Coal. Min. Eng. 50(12):28-32.

Baltpurvins, K.A., R.C. Burns, G.A. Lawrance, and A.D. Stuart. 1996. Effect of pH and anion type on the aging of freshly precipitated iron(III) hydroxide sludges. Environ. Sci. Technol. 30:939-944.

Bertsch, P., W. Miller, M. Anderson, and L. Zelazny. 1989. Coprecipitation of iron and aluminum during titration of mixed $\mathrm{Al}^{+}, \mathrm{Fe}^{3+}$, and $\mathrm{Fe}^{2+}$ solutions. Clays Clay Miner. 37:12-18.

Bigham, J.M., U. Schwertmann, and G. Pfab. 1996a. Influence of pH on mineral speciation in a bioreactor simulating acid mine drainage. Applied Geochemistry. 11:845-849.

Bigham, J.M., U. Schwertmann, S.J. Traina, R.L. Winland, and M. Wolf. 1996b.

Schwertmannite and the chemical modeling of iron in acid sulfate waters. Geochim. Cosmochim. Acta. 60:2111-2121.

Brady, K.S., J.M. Bigham, W.F. Jaynes, and T.J. Logan. 1986. Influence of sulfate on Feoxide formation: Comparisons with a stream receiving acid mine drainage. Clays Clay Miner. 34:266-274.

Breeuwsma, A. and J. Lyklema. 1973. Physical and chemical adsorption of ions in the electrical double layer on hematite $\left(\alpha-\mathrm{Fe}_{2} \mathrm{O}_{3}\right)$. J. Colloid Interface Sci. 43:437-448.

Brown, H., J. Skousen, and J. Renton. 1994a. Floc generation by chemical neutralization of acid mine drainage. Green Lands 24(1):44-51.

Brown, H., J. Skousen, and J. Renton. 1994b. Volume and composition of flocs from chemical neutralization of acid mine drainage. Green Lands 24(3):34-39.

Chang, L. and L. Cockerham. 1994. Chapter 4, Toxic Metals in the Environment. p. 115117. In L. Cockerham and B. Shane (ed) Basic Environmental Toxicology. CRC Press, Boca Raton, FL.

Connell, D. and G. Miller (ed.). 1984. Chapter 10, Metals and Salts. p. 288-332. In Chemistry and Ecotoxicology of Pollution. John Wiley \& Sons, Inc., New York.

Davies, S.H.R. and J.J. Morgan. 1989. Mn(II) oxidation kinetics on metal oxide surfaces. J. Colloid Interface Sci. 129:63-77. 
Dempsey, B.A. and B.-H. Jeon. 2001. Characteristics of sludge drained from passive treatment of mine drainage. Geochemistry: Exploration, Environment, Analysis. 1:8994.

Diem, D. and W. Stumm. 1984. Is dissolved $\mathrm{Mn}^{2+}$ being oxidized by $\mathrm{O}_{2}$ in absence of Mnbacteria or surface catalysts? Geochim. Cosmochim. Acta 48:1571-1573.

Diz, H.R., J.T. Novak, and J.D. Rimstidt. 1999. Iron precipitation in synthetic acid mine drainage. Mine Water and the Environment. 18:1-14.

Dousma, J. and P. de Bruyn. 1976. Hydrolysis-precipitation studies of iron solutions: I. Model for hydrolysis and precipitation from Fe(III) nitrate solutions. J. Colloid. Interface Sci. 56:527-539.

Dousma, J. and P. de Bruyn. 1978. Hydrolysis-precipitation studies of iron solutions: II. Aging studies and the model for precipitation from Fe(III) nitrate solutions. J. Colloid. Interface Sci. 64:154-170.

Dousma, J. and P. de Bruyn. 1979. Hydrolysis-precipitation studies of iron solutions: III. Application of growth models to the formation of colloidal $\alpha \mathrm{FeOOH}$ from acid solutions. J. Colloid. Interface Sci. 72:314-320.

Dousma, J., D. den Ottlander, and P. de Bruyn. 1979. The influence of sulfate ions on the formation of iron (III) oxides. J. Inorg. Nucl. Chem. 41:1565-1568.

Eaton, A.D., L.S. Clesceri, and A.E. Greenberg. 1995. Standard Methods for the Examination of Wastewater. $19^{\text {th }}$ ed. APHA/AWWA/WEF. Am. Public Health Assoc., Washington, DC.

Evangelou, V.P. 1990. Influence of water chemistry on suspended solids in coal-mine sedimentation ponds. J. Environ. Qual. 19:428-434.

Evangelou, V.P. 1998. Environmental Soil and Water Chemistry: Principles and Applications. John Wiley \& Sons, Inc., New York.

Evangelou, V.P. and A. Karathanasis. 1991. Influence of $\mathrm{pH}$, sodium adsorption ratio, and salt concentration on settling kinetics of suspended solids in coal-mine ponds. J. Environ. Qual. 20:783-788.

Ferrell, G.M. 1986. National Water Summary 1986. Ground-water quality: West Virginia. U.S. Geological Survey Water-Supply Paper 2325. U.S. Geological Survey, Charleston, WV.

François, R.J. and A.A. Van Haute. 1985. Structure of hydroxide flocs. Water Res. 19:1249-1254. 
Glasgow, L.A. 1989. Effects of physiochemical environment on floc properties. Chem. Eng. Prog. 85(8):51-55.

Glasrud, G.C., R.C. Navarrete, L.E. Scriven, and C.W. Macosko. 1993. Settling behavior of iron oxide suspensions. AIChE Journal. 39:560-568.

Gray, N. 1996. Environmental impact and remediation of acid mine drainage: A management problem. Environ. Geol. 30:62-71.

Herrera-Ramos, A.C. and M.B. McBride. 1996. Goethite dispersibility in solutions of variable ionic strength and soluble organic matter content. Clays Clay Miner. 44:286296.

Holtzen, M.L. and D.P. Smith. 1998. Minerals and mine drainage. Water Environment Research. 70:652-658.

HPT Research, Inc. 2000. Pilot AMD treatment system reduces sludge byproduct. Pollution Engineering. 32(13):45.

Kanungo, S.B. 1994. Adsorption of cations on hydrous oxides of iron I. Interfacial behavior of amorphous $\mathrm{FeOOH}$ and $\beta-\mathrm{FeOOH}$ (Akaganeite) in different electrolyte solutions. J. Colloid Interface Sci. 162:86-92.

Kleinow, K. and M. Goodrich. 1994. Chapter 13, Environmental Aquatic Toxicology. p. 361-362. In L. Cockerham and B. Shane (ed) Basic Environmental Toxicology. CRC Press, Boca Raton, FL.

Lagvankar, A.L. and R.S. Gemmel. 1968. A size-density relationship for flocs. J. Am. Water Works Assoc. 60:1040-1046.

Langmuir, D. 1997. Aqueous Environmental Geochemistry. Prentice-Hall, Inc. Upper Saddle River, NJ.

Lahann, R.W. 1976. Surface charge variation in aging ferric hydroxide. Clays Clay Miner. 24:320-326.

Lee, S-E., B. Koopman, H. Bode, and D. Jenkins. 1983. Evaluation of alternative sludge settleability indices. Water Res. 17:1421-1426.

Lindsay, W.L. 1979. Chemical Equilibria in Soils. John Wiley \& Sons, New York.

Macklin, M., K. Hudson-Edwards, and E. Dawson. 1997. The significance of pollution from historic metal mining in the Pennine orefields on river sediment contaminant fluxes to the North Sea. Sci. Total Environ. 194/195:391-397.

Maggard, R. and E. Kirk. 1999. Downstream impacts of surface mining and valley fill 
construction: Proc. West Virginia Surface Mine Drainage Task Force Symp., $20^{\text {th }}$, Morgantown, WV. 13-14 Apr. 1999. West Virginia Surface Mine Drainage Task Force and West Virginia Mining \& Reclamation Assoc., Morgantown, WV.

Melikhov, I., E. Kozlovskaya, L. Berliner, and M. Prokofiev. 1987. Kinetics of hydroxide Fe(III) solid phase formation. J. Colloid Interface. Sci. 117:1-8.

Michaels, A.S. and J.C. Bolger. 1962a. Settling rates and sediment volumes of flocculated kaolin suspensions. Ind. Eng. Chem. Fundam. 1:24-33.

Michaels, A.S. and J.C. Bolger. 1962b. The plastic flow behaviour of flocculated kaolin suspensions. Ind. Eng. Chem. Fundam. 1:153-162.

Moreno, N., X. Querol, C. Ayora, C.F. Pereira, M. Janssen-Jurkovicova. 2001. Utilization of zeolites synthesized from coal fly ash for the purification of acid mine waters. Environ. Sci. Technol. 35:3526-3534.

Nakamura, T. and H. Kurokawa. 1995. Preparation of monodispersed haematite particles by two-step hydrolysis of ferric chloride aqueous solutions. J. Mater. Sci. 30:4710-4714.

Nordstrom, D.K. 1991. Chemical modeling of acid mine waters in the western United States. USGS Water Res. Invest. Rep. No. 91-4034, U.S. Geological Survey, p. 534-538.

Parfitt, R.L. and R.S.C. Smart. 1978. The mechanism of sulfate adsorption on iron oxides. Soil Sci. Soc. Am. J. 42:48-50.

Parida, K. and J. Das. 1996. Studies on ferric oxide hydroxides: Effect of sulfate ions on the formation and physico-chemical properties of ferric oxide hydroxides prepared by a homogenous precipitation method. Part 1. J. Mater. Sci. 31:2199-2205.

Parks, G. 1965. The isoelectric points of solid oxides, solid hydroxides, and aqueous hydroxo complex systems. Chem. Rev. 65:177-198.

Peck, M., G. Cole, and C. Smith. 1979. Acid-mine-water problems in northern Appalachia. Mountain State Geology. WV Geological and Economic Survey, Morgantown, WV.

Persson, P. and L. Lovgren. 1996. Potentiometric and spectroscopic studies of sulfate complexation at the goethite-water interface. Geochim. Cosmochim. Acta. 60:27892799.

Przepiora, A., D. Hesterberg, J. Parsons, J. Gilliam, D. Cassel, and W. Faircloth. 1997. Calcium sulfate as a flocculant to reduce sedimentation basin water turbidity. J. Environ. Qual. 26:1605-1611.

Rajan, S.S.S. 1978. Sulfate absorbed on hydrous alumina, ligands displaced, and changes in surface charge. Soil Sci. Soc. Am. J. 42:39-44. 
Rikard, M. and S. Kunkle. 1990. Sulfate and conductivity as field indicators for detecting coal-mining pollution. Environ. Monit. Assess. 15:49-58.

Rose, A. and C. Cravotta, III. 1998. Geochemistry of coal mine drainage. p. 1-1 - 1-22. In Coal Mine Drainage Prediction Prevention in Pennsylvania. 5600-BK-DEP2256. Pennsylvania Department of Environmental Protection.

Rose, S. and A.M. Ghazi. 1997. Release of sorbed sulfate from iron oxyhydroxides precipitated from acid mine drainage associated with coal mining. Environ. Sci. Technol. 31:2136-2140.

Schwertmann, U. and E. Murad. 1983. Effect of $\mathrm{pH}$ on the formation of goethite and hematite from ferrihydrite. Clays Clay Miner. 31:277-284.

Singer, P. and W. Stumm. 1970. Acidic mine drainage: The rate determining step. Science. 167:1121-1123.

Singh, B., P. Harris, and M. Wilson. 1997. Geochemistry of acid mine waters and the role of micro-organisms in such environments: A review. Adv. GeoEcol. 30:159-192.

Singh, U. and G. Uehara. 1986. Electrochemistry of the Double-Layer: Principles and Applications to Soils. p. 1-38. In D.L. Sparks (ed.) Soil Physical Chemistry, CRC Press, Boca Raton, FL.

Skousen, J. 1988. Chemicals for treating acid mine drainage. Green Lands 18(2):36-48.

Skousen, J. 1996. Coal mining in West Virginia and the passage of SMCRA. p. 5-12. In J. Skousen and P. Ziemkiewicz (ed.) Acid mine drainage: control and treatment, $2^{\text {nd }}$ ed. West Virginia Univ. and the National Mine Land Reclamation Center: Morgantown, WV.

Sposito, G. 1981. The operational definition of the zero point of charge in soils. Soil Sci. Soc. Am. J. 45:292-297.

Steed, V., M. Suidan, M. Gupta, T. Miyahara, C. Acheson, and G. Sayles. 1996. Development of a sulfate-reducing bioprocess to remove heavy metals from acid mine drainage. Proc. $69^{\text {th }}$ Water Environ. Fed. Tech. Annu. Conf. Exposition, Dallas, TX.

Stewart, D., T. Norman, S. Cordery-Cotter, R. Kleiner, and E. Sweeney. 1997. Utilization of a ceramic membrane for acid mine drainage treatment. Proc. Int. Conf. Tailings Mine Waste, Balkema, Rotterdam, Neth. 4:453-460.

Stuart, B., R. Ramachandran, and J. Grow. 1999. Impact of acid mine drainage on streams in Southeastern Ohio: Importance of biological assessments: Proc. West Virginia Surface Mine Drainage Task Force Symp., 20 ${ }^{\text {th }}$, Morgantown, WV. 13-14 Apr. 1999. 
West Virginia Surface Mine Drainage Task Force and West Virginia Mining \& Reclamation Assoc., Morgantown, WV.

Stumm, W. and J.J. Morgan. 1981. Aquatic Chemistry $2^{\text {nd }}$ ed. John Wiley \& Sons, New York.

Sumner M.E. and W.P. Miller. 1996. Cation exchange capacity and exchange coefficient. p. 1201-1229. In: D.L. Sparks, et al. (ed.), Methods of Soil Analysis: Part 3. Series 5. Chemical Methods. SSSA and ASA, Madison, WI

Sung, W. and J.J. Morgan. 1980. Kinetics and product of ferrous iron oxygenation in aqueous systems. Environ. Sci. Technol. 14:561-568.

Sutherland, D.N. 1966. Comments on Vold's simulation of floc formation. J. Colloid Interface Sci. 22:300-302.

Sutherland, D.N. 1967. A theoretical model of floc structure. J. Colloid Interface Sci. 25:378380.

Sutherland, D.N. and I. Goodarz-Nia. 1971. Floc simulation: the effect of collision sequence. Chem Eng. Sci. 26:2071-2085.

Tambo, N. and Y. Watanabe. 1979. Physical characteristics of flocs- I. The floc density function and aluminum floc. Water Res. 13:409-419.

Tyson, R. 1997. Pennsylvania coal mine reclamation plan to use contaminated harbor sediments. Environ. Sci. Technol. 31:457A.

van de Ven, T.G. and R.J. Hunter. 1977. The energy dissipation in sheared coagulated sols. Rheol. Acta 16:534-543.

Vold, M.J. 1963. Computer simulation of floc formation in a colloidal suspension. J. Colloid Sci. 18:684-695.

Waldron, M. 1991. National Water Summary 1990-1991. Stream water quality: West Virginia. U.S. Geological Survey Water-Supply Paper 2400. U.S. Geological Survey, Charleston, WV.

Waybrant, K.R., D.W. Blowes, and C.J. Ptacek. 1998. Selection of reactive mixtures for use in permeable reactive walls for treatment of mine drainage. Environ. Sci. Technol. 32:1972-1979.

Yernberg, W.R. 2000. Improvements seen in acid-mine-drainage technology. Min. Eng. 52(9):67-70.

Zelazny, L., L. He, and A. Vanwormhoudt. 1996. Charge analysis of soils and anion 
exchange. p. 1231-1253. In D.L. Sparks (ed.) Methods of Soil Analysis: Part 3. Series 5. Chemical Methods. SSSA and ASA, Madison, WI.

Zhou, Z., J. Bateman, A. Babchin, and G. Bird. 1994. Characterization and settling of solid contaminants in coal mine effluent. J. Environ. Qual. 23:746-751. 